\title{
Development of Slope Deformation Monitoring System Based on Tilt Sensors with Low Power Wide Area Network Technology and Its Application
}

\section{Aulia Dharma Putra ( $\square$ auliadputra89@gmail.com )}

Ehime Daigaku Kogakubu Daigakuin Rikogaku Kenkyuka

Hikaru Toda

Ehime Daigaku Kogakubu Daigakuin Rikogaku Kenkyuka

Achmad Hafidz

Ehime Daigaku Kogakubu Daigakuin Rikogaku Kenkyuka

Kouji Matsuba

Dia Consultants Co., Ltd

Yuuichi Kimikado

Ryoden Corporation

Yoshinori Takahashi

Green House Co., Ltd

Shinji Tsuzuki

Ehime Daigaku Kogakubu Daigakuin Rikogaku Kenkyuka

Naoki Kinoshita

Ehime Daigaku Kogakubu Daigakuin Rikogaku Kenkyuka

Hideaki Yasuhara

Ehime Daigaku Kogakubu Daigakuin Rikogaku Kenkyuka

\section{Research Article}

Keywords: Tilt sensor, slope monitoring, LPWA (Low Power Wide Area), slope failure, rainfall

Posted Date: June 4th, 2021

DOI: https://doi.org/10.21203/rs.3.rs-216346/v1

License: (c) (i) This work is licensed under a Creative Commons Attribution 4.0 International License.

Read Full License 


\title{
Development of Slope Deformation Monitoring System Based on Tilt Sensors with Low Power Wide Area Network Technology and Its Application
}

\author{
Aulia Dharma Putra ${ }^{1 *}$, Hikaru Toda ${ }^{1}$, Achmad Hafidz $^{1}$, Kouji Matsuba $^{2}$, Yuuichi Kimikado ${ }^{3}$, Yoshinori Takahashi ${ }^{4}$, \\ Shinji Tsuzuki ${ }^{1}$, Naoki Kinoshita ${ }^{1}$, Hideaki Yasuhara ${ }^{1}$ \\ ${ }^{1)}$ Department of Civil and Environmental Engineering, Ehime University, Matsuyama 790-8577, Japan \\ ${ }^{2)}$ Dia Consultant Co., Ltd, Matsuyama 790-0952, Japan \\ ${ }^{3)}$ Ryoden Corporation, Matsuyama 790-0002, Japan \\ ${ }^{4)}$ Green House Co., Ltd, Tokyo 150-0013, Japan \\ *Corresponding author: auliadputra89@gmail.com
}

\begin{abstract}
A simple monitoring method for observing slope movement and deformation can be performed with tilt sensors. A more efficient monitoring method, using a type of wireless communication called LPWA (Low Power Wide Area) network technology, has also recently become available. In the present study, a monitoring system was developed that combines tilt sensors and LPWA network technology for measuring the movement of slopes and sending the information through wireless communication. Firstly, radio wave propagation experiments were conducted to find the proper location for the gateway device of the monitoring system. Then, in March 2018, the developed system that consists of tilt and water-level sensors and the wireless communication of LPWA was installed at an observation site. Since the installation, the data from the tilt sensors have been successfully collected through LPWA, and a slope failure was unexpectedly observed at the observation site during the Heavy Rain Event of July 2018, which caused severe disasters, particularly from western Japan to the Tokai region. Using the data from the tilt sensors, the rainfall data, and the groundwater level, the slope failure was analysed. A site investigation was conducted, and the shear strength parameter was examined using back analysis method. In conclusion, the developed system using sensors and LPWA has continued to efficiently monitor the movement of the targeted slope, but the collection of additional data will be required to increase the reliability of the system.
\end{abstract}

Keywords: Tilt sensor, slope monitoring, LPWA (Low Power Wide Area), slope failure, rainfall

\section{Introduction}

Mountainous areas occupy approximately $70 \%$ of the country's land in Japan, and different types of slope failures have frequently occurred due to natural disasters such as typhoons, heavy rain events, earthquakes, floods. In July 2018, a large number of landslides occurred due to torrential rains that caused enormous damage in various places. Their total number was 50 cases. They occurred in western Japan, in Hiroshima, Ehime, Hyogo, and Kochi Prefectures (Ministry of Land, Infrastructure and Transport 2018).

In order to reduce the damage caused by slope failures as much as possible, it is necessary to establish monitoring methods for observing slope movement and sending the information through communication systems regardless 
of the weather and temperature conditions. The conventional systems have been using wired cables for the power supply and for transmitting the data to the equipment.

Wireless technology is one of the new and efficient techniques for the real-time monitoring of areas at risk. The successful implementation of a slope movement detection device requires the treatment of massive amounts of data from a wireless sensor network, the maintenance of its accuracy and integrity, and the assurance of the lowlatency transmission of the sensed data with the efficient utilization of energy (Ramesh 2014).

Many options are available for the monitoring of unstable slopes, from inexpensive and short-term solutions to more expensive and long-term solutions. The increase in locations with unstable slopes has created a need for monitoring systems that can be accessed remotely and can provide the data to make a reliable system (Kane and Beck 2001). With advances in electronic instrumentation and telecommunication, it is now possible to monitor slopes at low cost. The use of tilt sensors for early warning is a newly proposed technique. Unlike extensometers, however, which have a long history with vast experience, the monitoring data obtained by tilt sensors are limited. The tilting behaviour in the pre-failure stages of slopes may depend on the site conditions as well as the positions of the sensors, and more data collection may be required for the further refinement of this early warning method. A wireless sensor unit, that employs tilt sensors, was developed and installed on several real slopes in Japan and China, and long-term monitoring has been attempted (Uchimura et al. 2015).

LPWA (low power wide area) network technology is a communication method that achieves long-distance communication with minimum power consumption. It is drawing attention nowadays as one of the components of the Internet of Things (IoT) (Adelantado et al. 2017). The current work introduces a slope monitoring system using LPWA technology. LPWA is a long-range, low-power, low-bitrate, wireless telecommunications system promoted as an infrastructure solution for the IoT: end-devices use LPWA across a single wireless hop to communicate to a gateway, connected to the internet, which act as transparent bridges and relay messages between these end-devices and a central network server (Augustin et al. 2016). LPWA is designed for sensors and applications that need to send large amounts of data over long distances a few times per hour from varying environments and contains a battery with a multi-year lifetime (Sinha et al. 2017; Song et al. 2017; Mekki et al. 2019).

In this study, a slope monitoring system has been developed using LPWA network technology. The system was installed at an observation site to examine its validity (Figure 1). This study comprised several stages. Firstly, radio wave propagation experiments were conducted to examine the workability of the adopted LPWA and to determine the proper location for the LPWA system's gateway device (receiver). Secondly, tilt sensors with LPWA end nodes (transmitters) were installed at an observation site. Thirdly, the movement of the slope was monitored and the inclination data were collected to examine the monitoring system. During the monitoring, a surface slope failure occurred due to extreme rainfall during a heavy rain event in July 2018, and the failure was captured by the system. Therefore, the obtained data, before and at the moment of the failure, are shown in this study and the stability analyses are explained.

\section{Radio Wave Propagation Experiments}

The LPWA network, using LoRa or Sigfox, etc., allows for long-range, low-power, and low throughput communications. In Japan, LPWA operates on 920-MHz ISM bands and can be used without the license of a radio 
station. The propagation distance is very wide; it may be greater than $10 \mathrm{~km}$. One aim in using this system is that it be usable in long-life battery-powered devices, where energy consumption is of paramount importance.

Before the monitoring system was installed in the Tachiyama area, the proper location for the gateway device (i.e., receiver) had to be chosen for receiving and sending data. Four locations were selected as candidate sites for the receiver. Each location was selected based on the possibility of receiving radio waves and also of providing electricity to generate the receiver. The elevation and distance from the transmitter (monitoring site) to the candidate sites are shown in Table 1.

\subsection{Methodology}

Firstly, the transmitter (Figure 2) was placed roughly $10 \mathrm{~m}$ away from the observation site. After the placing of the transmitter, the gateway devices were brought from the transmitter to each candidate site. For the equipment, built-in RM-92A and Arduino Uno with a mobile battery were used for the transmitter (Figure 2). The transmission interval for sending radio waves was set to be 1 second. During the transportation to the candidate sites, information on the locations of the gateway devices was recorded using GPS (Global Positioning System) applications. When arriving at the candidate sites, the reception of the radio waves was checked.

The results of the radio wave propagation are shown in Figure 3. The RSSI (Received Signal Strength Indicator) value is used as an index to indicate whether radio waves can be received or not. The RSSI value represents the reception sensitivity; it also indicates the strength of the radio waves. In Figure 3, the black line shows the trajectory of transportation. As shown in Figure 3, the radio waves were received near the observation site and at Location 4. Meanwhile, other locations did not receive any radio waves from the transmitter. As shown in Table 1, the distance between Location 1 and the observation site was $15.40 \mathrm{~km}$. The great distance between Location 1 and the observation site caused a decrement in signal strength due to attenuation. The attenuation of the signal happens due to it having to pass through several materials, which depends on the dielectric constant and electrical conductivity of the material (Qureshi et al. 2016). Even though the distance from the observation site to location 2, location 3 and location 4 was quite similar, location 2 and location 3 could not receive any radio waves from the transmitter due to the presence of a hill that should block the reception of the radio waves. At the observation site, the received RSSI values fell in the range of -137 to $-60 \mathrm{dBm}$. At Location 4 , the maximum RSSI value received from the observation site was $-104 \mathrm{dBm}$. From the results of the radio wave experiments, it can be concluded that the only suitable place for the gateway device is at Location 4, which has an elevation of around $850 \mathrm{~m}$ above sea level and is $8.20 \mathrm{~km}$ from the observation site.

\subsection{Transmissivity from Observation Site}

Radio wave propagation experiments from the site where the tilt sensors would be installed were conducted. Ten units (A to J) were used to set the tilt sensors on top of the piles at the site (Figure 4). A transmitter (Figure 2) was placed at each point and it was confirmed whether or not the radio waves could be received by the receiver that was set up at Location 4. The equipment which was used for the transmissivity was similar to and had the same performance as that of the previous experiments.

For the experiments, two places at Location 4 were examined. One was in the observation building (Point A) and the other was at the top of the radio tower (Point B) (Figure 5). The gateway device was placed at those two points, and the transmissivity was evaluated. 
The RSSI values obtained at Points A (observatory) and B (radio tower) are shown in Figure 6. When the transmitter was installed at the ten locations (A to J), the RSSI values of Point A fell in the range of -100 to -131 $\mathrm{dBm}$, and it was confirmed that radio waves were received at Point A without any problems. For the second experiment, the receiver was installed at the top of the radio tower (Point B). It was expected that there would be a higher possibility of receiving radio waves there due to the higher location. The experimental results (Figure 6) showed that the RSSI values of Point B (from A to J) fell in the range of -70 to $-90 \mathrm{dBm}$. Based on that radiowave experiment, it was concluded that the radio tower at Location 4 would be the most suitable place to receive radio wave communication from the transmitter. Therefore, the gateway device was installed at that location.

\section{Monitoring Slope Movement}

The Tachiyama area of Ehime Prefecture, Japan, was chosen to study the monitoring slope movement (Figure 7). Several landslides have occurred at the Tachiyama area since 2004. Consequently, the areas where landslides occurred in the past and their surroundings have a high probability of slope failures during heavy rainfall (Park et al. 2016). Thus, ten tilt sensors were installed at the Tachiyama area. As shown in Figure 4, all the tilt sensors except sensor A are located in the unstable area which is bordered by a tension crack. The presence of the tension crack can also decrease the stability of a slope (Li et al. 2018). Therefore, the slope movement at the Tachiyama area were monitored using this slope monitoring system.

The data from the tilt sensors using the LPWA were transferred to the gateway unit installed at Location 4. The gateway unit collects the data from all the sensors and sends them to the network server through the $3 \mathrm{G}$ Internet. After installing the gateway device, each end-node with a tilt sensor, and the LPWA transmitter, were placed using a steel rod (Figure 8). Then, the monitoring was started on 1 March 2018. It should be noted that the inclination values measured by the tilt sensors were transmitted once every 10 minutes, the resolution of the measurement was $0.01^{\circ}$, and the data and the information could be monitored through the website (Figure 9).

The locations where the sensors were installed can be found on the left-hand side of the homepage (Figure 9). The yellow triangles represent the locations of the installed tilt sensors and the letters next to them are the tilt sensor names. The red circles on Sensors C, E, F, and I show the locations where the in-situ inclinometers were installed. The displacement data were obtained from these in-situ inclinometers. Moreover, the blue circle on Sensor F represents the groundwater level sensor. On the right-hand side of the homepage, the latest data on the inclination, temperature, water level, and remaining battery level of each sensor can be found. By clicking on each sensor, a graph with the temporal changes in inclination, water level, and temperature can be seen.

\subsection{Tilt Sensor Data}

In this study, the tilt sensors were installed at the Tachiyama area to monitor the slope movement. The tilt sensor was chosen for several reasons. Firstly, the tilt sensor has high serviceability since its installation and operation are easier and less time-consuming than the extensometer (Uchimura et al. 2015). Secondly, a tilt sensor can be applied to monitor rotational landslides and shallow translational landslides (Qiao et al. 2020). Thirdly, the tilting behaviour of the slope from the tilt sensor in the acceleration stage can be used to predict the time of slope failure (Xie et al. 2019). Finally, a linear relationship between the displacement of the slope surface and the tilting angle from the tilt sensor in shallow landslides was detected (Xie et al. 2019). Therefore, the displacement of the slope surface can be predicted using the tilt angle data. 
Even though the tilt sensor has some advantages, the tilt sensor is not suitable for monitoring the slow-moving landslide since the movement of the slope is very slow, which is less than $18 \mathrm{~mm} /$ year (Varnes 1978). For example, the vertical and horizontal displacement on the Taukliman coastal landslide is up to $0.2 \mathrm{~mm} / \mathrm{year}$ (Klimes et al. 2011). Therefore, the slow-moving landslide may be difficult to detect using the tilt sensor since the measurement of the tilt sensor can be affected by the ambient temperature.

Based on the information above, the tilting angle of a slope can be considered as an important indication of slope failure. Uchimura et al. (2015) propose the tilting rate that can be used as a precaution or a warning indication for a slope failure. The tilting rate for the precaution and the warning indication for a slope failure are $0.01 \%$ hour and $0.1^{\circ}$ hour, respectively. This warning indication is very important since the duration before slope failure was less than 10 hours when a tilting rate of $0.1 \%$ hour was observed (Uchimura et al. 2015). In this study, the measurement resolution of the tilt sensor is $0.01^{\circ}$. Therefore, the tilt sensor can be used to provide a precaution or warning indication for a slope failure.

The overall monitoring data representation of the tilt sensors on the homepage using the LPWA system is shown in Figure 9. Real-time data are provided by embedded systems in order to monitor the slope movement. During the monitoring, some errors in the measurements have been found. The measurement errors occurred for several reasons, such as changes in temperature, disruption by animals, and the end of the lifetime of the batteries. The specifications of tilt sensors include their sensitivity to rapid changes in temperature. In this study, the tilt sensor uses the hall effect to measure the tilt angle. A hall effect sensor is a semiconductor device that converts a magnetic field to electric voltage (Ali et al. 2017). Temperature can affect the sensitivity of the hall effect sensor since the temperature influences the conductivity of semiconductor material (Feng et al. 2007). Sensitivity is defined as the responsivity of the output voltage of the hall device to a magnetic field (Ali et al. 2017). Therefore, a laboratory experiment was conducted to investigate the correlation between tilt sensor data and the ambient temperature. In this laboratory experiment, the tilt sensor was put in an oven at temperatures from 21 to $56^{\circ} \mathrm{C}$. Based on laboratory experiments, the linear relationship between the temperature and the tilt sensor data was observed with a coefficient of determination (R2) of 0.965, as shown in Figure 10. Based on the information above, the variation in temperature can bring about measurement errors. Therefore, a temperature sensor, with the resolution of $0.25^{\circ}$, was also set to observe the changes in temperature at the Tachiyama area. The most common technique for temperature compensation is polynomial curve fitting. However, linear curve fitting can also be used for temperature compensation since the linear curve can be considered as a derived form of polynomial curve fitting (Ali 2014). However, each sensor has its own temperature dependence. Therefore, a laboratory experiment should be conducted to generate the linear curve fitting for each sensor.

In this study, a laboratory experiment for each sensor was not conducted since the significant temperature effect on the tilt sensor data was recently recognized after the tilt sensors were installed in March 2018. Thus, it is not easy to conduct a laboratory experiment to generate the linear curve fitting for each sensor. However, the linear curve fitting still can be obtained using the tilt sensor data and temperature data from the Tachiyama area if it is assumed that the changes of tilt angle in the absence of rainfall are the changes due to ambient temperature fluctuation. Nevertheless, the heavy rainfall occurred from March to July 2018, with monthly rainfall up to 150 $\mathrm{mm}$. Consequently, the tilt sensor data before the slope failure event cannot be used to generate the linear curve fitting for each sensor. 
Furthermore, the monthly rainfall in October 2018 is only $42 \mathrm{~mm}$. Therefore, the tilt sensor data and temperature data can be used to generate the linear curve fitting. For example, the tilt sensor and temperature data at sensor B, the Tachiyama area, were shown in Figure 11. As shown in Figure 11, a high relationship between the temperature and tilt sensor data was observed with a coefficient of determination $\left(\mathrm{R}^{2}\right)$ of 0.925 . Moreover, the linear curve fitting was applied to the tilt sensor as the temperature compensation. The result showed the linear curve fitting was successfully applied to reduce the temperature effect on the tilt sensor data. Although the linear curve fitting was successful, a slight fluctuation in tilt sensor data still appears. This slight fluctuation may be caused by random noise. One of the methods that can be applied to tilt sensor data in order to remove the random noise is the moving average filter (Ali 2014). As shown in Figure 11, the tilt sensor data is smoothed using a 145-points moving average filter.

\section{Field Tests and Laboratory Tests}

\subsection{Visual Site Inspection and Measurement with Site Investigation}

A site survey was carried out to closely examine the mechanism of the failure. From the site investigation, the location of the failure was identified. Figure 12 shows the observation site, before and after the failure occurred, where Sensor $\mathrm{H}$ had been installed. The initiation of the slope failure was found at a height of $23 \mathrm{~m}$ from the slope base. The observation site has slope gradients of more than $40^{\circ}$. According to the topography of the site, the water flow on surface from the top made the soil unstable.

A close inspection and direct measurements using a tape measure and rangefinder were conducted. The rangefinder is a device that measures the distance from the observer to a target in a process called ranging. After the data measurements had been performed, a model of the slope failure was made from a topography map. The model is shown in Figure 13.

According to the topography map (Figure 13), the observation site was divided into two parts, stable and unstable areas. The thick grey line is the mark that separates the two areas. Sensor A was installed outside the grey area to monitor the inclination in the stable area. The other sensors were installed inside the unstable (moving) area. Based on the topography, it is seen that some collapses may have occurred a long time ago; they are marked by thin grey lines. The orange-lined area represents the location where the failure occurred due to the heavy rainfall event in July 2018. The failure area is around $107 \mathrm{~m}^{2}$ with a depth of failure ranging from 1 to $2 \mathrm{~m}$. To determine the soil characteristics of the collapsed land around the slope failure area, simple cone penetration tests, field density tests, and soil particle size distribution tests were conducted. Strength parameters was obtained by using back analysis method (Wesley and Leelaratnam 2001).

\subsection{Field Tests with Standard Penetration Tests (SPT) and Dynamic Cone Penetration Tests (DCPT)}

A standard penetration test (SPT) was carried out since the SPT test is one of the most common in-situ tests to identify soil type and stratigraphy along with being a relative measure of strength during site investigation (Yusof and Zabidi 2018). The SPT is common to use for the preliminary soil investigation (Tarawneh 2017). The number of blows is counted until the sampler reaches $150 \mathrm{~mm}$ in depth to obtain the SPT number. A $63.5 \mathrm{~kg}$ driving hammer is used to drive the sampler by falling it from a height of $760 \mathrm{~mm}$ (Bowles 1996). 
The SPT was conducted at two locations (SPT-1, SPT-2, Figure 13). The test at SPT-1 was conducted within the collapsed area, while the test at SPT-2 was conducted in a non-collapsed area. The test results are shown in Figure 13. At SPT-1, the $\mathrm{N}$ value was 8 at a depth of $1.3 \mathrm{~m}$ and 50 at a depth of $3.3 \mathrm{~m}$. At B-02, the $\mathrm{N}$ value was 50 at a depth of $6 \mathrm{~m}$.

Furthermore, exploratory borings were conducted at three locations (B-1, B-2, B-3, Figure 13). A cross-section of the observation site can be obtained using the boring logs as shown in Figure 15. It is found that the observation site consists of three types of soils which are colluvial soils, debris flow soil and weathered rock.

For detailed soil investigation, dynamic cone penetration tests (DCPT) were also carried out around Sensor H since DCPT is a rapid inexpensive field test that can be used to assess the engineering properties of soils (Ishtiwi 2016). The DCPT was conducted based on JGS (Japanese Geotechnical Society) 1433 standards. The tests employed two 16-mm diameter boreholes coupled near the midpoint. The lower shaft contained an anvil and a pointed tip. The hammer weight was no rebound-type and weighed $5 \pm 0.05 \mathrm{~kg}$. The stainless-steel rods were 16 $\mathrm{mm}$ in diameter and $0.5 \mathrm{~m}$ in length. During the cone penetration test, the sliding hammer was dropped (free fall) from a height of $50 \mathrm{~cm}$ onto the anvil, as shown in Figure 16. The number of drops $\left(\mathrm{N}_{\mathrm{d}}\right)$ was recorded for each 10 $\mathrm{cm}$ penetration depth of the cone tip (Yang et al. 2015).

To determine the thickness and the volume of the collapsed soil by discriminating the collapsed soil from the original ground, a series of DCPT tests was carried out at the site of the embankment after the collapse, and at the site without deposits near the slope. DCPT tests were conducted at four locations (DCPT-1, DCPT-2, DCPT-3, DCPT-4, Figure 13). The test at DCPT-01 was conducted in a non-collapse area, but in the vicinity of the collapsed area, while the tests at DCPT-02 to DCPT-04 were conducted within the collapsed area.

The test results are shown in Figure 17. At DCPT-1, the top of the collapse area, the N value was less than 11 at a depth of $0.7 \mathrm{~m}$ and more than 27 at a depth of $0.8 \mathrm{~m}$. It is thought that the hard surface for the top area is around $0.8 \mathrm{~m}$ since the great $\mathrm{N}$ value indicates a high dry soil density (Mansour et al. 2019). The hard layer where the cone could not penetrate the soil was deeper than $2 \mathrm{~m}$. At DCPT-2, the $\mathrm{N}$ value at the depth of $0.7 \mathrm{~m}$ was 18 which is approximately twofold of that at $0.6 \mathrm{~m}$. At DCPT-3, the soft layer of soil may be shallower than $0.7 \mathrm{~m}$. At DCPT-4, there is a significant difference of $\mathrm{N}$ value between the depths of $0.7 \mathrm{~m}$ and $0.8 \mathrm{~m}$. A soft layer, shallower than $0.8 \mathrm{~m}$, may have formed due to the soil deposition of the collapsed slope.

As shown in Figure 18, the slope model failure has been measured using tape measurement and DCPT. The blue line represents the model slope measure by rangefinder and tape measurement. The grey area represents the soft layer evaluated from the DCPT tests. The lower half of the area is covered by landslide deposits. This layer has a depth of around $0.6-0.7 \mathrm{~m}$. The red line represents the hard layer where the DCPT cone could not penetrate the soil.

\subsection{Displacement Data}

Slope stability analyses and monitoring involve choosing certain parameters and then observing how they change with time. Two important parameters are the groundwater level and the displacement. Slope displacement can be characterized by the depth of failure planes, the direction, the magnitude, and the rate. One or all of these variables may be monitored. Conventional slope monitoring utilizes a single method or a combination of methods. In-situ tilt sensors are used to measure the horizontal movement below the ground surface. 
The simple shear probe consists of a thin-wall polyvinylchloride (PVC) pipe installed in a nominally vertical borehole. The curvature is determined by inserting a series of rigid rods of various lengths and measuring the depth at which each rod stops. The device is typically used as a failure plane indicator. The tilt sensor is attached to extension tubes, $4 \mathrm{~m}$ to $10 \mathrm{~m}$ in length, connected by flexible couplings to guide it down the pipe. At the top of the pipe, the tubes are connected to a dioptre dial. This dial, which indicates the orientation of the tilt sensor, enables the measurement of the movements in a predetermined direction or the direction of the maximum deflection. By this method, the location of Sensors F and I have been measured every month since February 2018. The results of the displacement are shown in Table 2.

Table 2 shows that every month the soil has moved slightly. From February 2018 until June 2018, the rate of movement was around 1-3 mm per month. From June 2018 until July 2018, when the torrential rain occurred, the deformation increased drastically. The displacement was around $13 \mathrm{~mm}$ at sensor F, while it was around $6 \mathrm{~mm}$ for Sensor I. It should be notice that the slope failure occurred at sensor H during the torrential rain.

\subsection{Particle Size Distribution}

Particle size distribution tests were conducted to determine the distribution of particle size in the soil. The tests were performed according to JIS (Japan Industrial Standard) A 1204. The soil particle size distribution is determined by the sedimentation process for soil particles with a particle size smaller than $75 \mu \mathrm{m}$, and by sieving for soil particles with a particle size larger than $75 \mu \mathrm{m}$.

Firstly, hydrometer tests were conducted using a 2-mm sieve. The soil samples were collected from seven locations, as shown in Figure 13, at a depth of around $10 \mathrm{~cm}$ from the surface.

Figure 19 shows the particle size distribution results. As shown in the figure, $40 \%$ of the soil at Points S-2, S-5, and S-7 have similar particle size distributions, namely, the fine particle size of $0.075 \mathrm{~mm}$. The soil at Points S-3, S-4, and S-6 have a fine grain content of about 20\%, which is lower than the other points. The proportion of soil at Point 1 having the particle size of $0.075 \mathrm{~mm}$ is more than $40 \%$.

Table 3 shows the classification of the soil properties based on the sieve analysis. The coefficient of uniformity, $\mathrm{Cu}$, must be greater than 4 for gravel and greater than 6 for sand, while the coefficient of curvature, Cc, must be between 1 and 3. Based on the coefficients of uniformity and curvature, the classification of the soil properties is judged overall to be poorly graded.

\section{Slope failure mechanism}

\subsection{Record of Tilt Sensor and Rainfall Data}

While collecting and gathering the data from the tilt sensors, a torrential rainfall occurred on Shikoku Island in July 2018. Due to the intense rainfall, a slope failure occurred at the observation site. The rainfall data were collected by the Japan Meteorological Agency around the observation site. Figure 20 presents the rainfall precipitation per hour 2 days before and after the slope failure. It shows that the highest precipitation of 30 $\mathrm{mm} /$ hour occurred on 7 July 2018.

At that time, some measurements from the tilt sensors were noticed. Figure 20 shows the results of the slope monitoring measurements during the heavy rain and the precipitation data measured by the Japan Meteorological Agency near the observation site. At 7:24 on 7 July, when the highest precipitation occurred, the inclination angle 
suddenly increased to $1.61^{\circ}$ at Sensor F. In addition, at 7:41 on 7 July, the inclination angle also abruptly increased to $0.37^{\circ}$ at Sensor H. Furthermore, the measurement data of Sensor H was interrupted at 15:27 on 7 July, indicating that some abnormality had occurred in the measurement system. It was confirmed as a slope failure by a subsequent site investigation.

\subsection{Record of Groundwater Level}

From the groundwater level sensor that was installed at the same point as Sensor F, data on the groundwater level during the heavy rainfall were obtained. Figure 20 shows the measured groundwater level and the rainfall intensity per hour at the observation site. As shown in this figure, a significant rise in the groundwater level was measured during the observation period. It occurred at 15:00 on 6 July. The highest peak of the groundwater level was around $7.1 \mathrm{~m}$ below the ground surface. The rainfall intensity per hour showed two peaks, while the groundwater level showed one peak. After the rain stopped on 7 July 2018, the groundwater level monotonically decreased with time.

\subsection{Back Analysis}

The back analysis is a method to obtain shear strength parameters when slope failure happens. The slip surface in the back analysis is assumed to be circular (Wesley and Leelaratnam 2001). Based on Figure 22, the assumed slip surface was identified to be compatible with the observed slip surface obtained from the site investigation. The slope stability analysis was used in this back analysis.

The limit equilibrium method (LEM) is still the most popular slope stability analysis method for slope stability problems (Burman et al. 2015). This method is usually analysed by discretizing the mass of the failure slope into smaller slices and treating each slice as a unique sliding block. All slope stability analyses use the limit equilibrium method, including Bishop method (Robert et al. 1997). This method satisfies vertical force equilibrium for each slice and overall moment equilibrium about the center of the circular slip surface (Rabie 2014). This Bishop method is an effective and simple method to analyse circular slip surfaces (Lin et al. 2014). The safety factor can be calculated using the following equation.

$$
S F=\frac{\sum_{i=1}^{i=n}\left[c b_{i}+\left(W_{i}-u_{i} b_{i}\right) \tan \phi\right]\left(\frac{1}{\cos \theta_{i}\left(1+\tan \theta_{i} \tan \phi / F\right)}\right)}{\sum_{i=1}^{i=n} W_{i} \sin \theta_{i}}
$$

where $S F$ is the safety factor, $c$ is the cohesion $\left(\mathrm{kN} / \mathrm{m}^{2}\right), \phi$ is the friction angle $\left(^{\circ}\right), b_{i}$ is the arch length of the -i slice, $W_{i}$ is the weight of the -i slice $(\mathrm{kN}), u_{i}$ is the water pore pressure of the $-\mathrm{i}$ slice $\left(\mathrm{kN} / \mathrm{m}^{2}\right)$, and $\theta_{i}$ is the angle of the slice $\left(^{\circ}\right)$.

The safety factor is usually used for slope engineering when assessing slope stability. Based on the concept of the safety factor, a safety factor value of 1.00 is considered the critical value for determining the slope stability. In contrast, the value of less than 1.00 means an unstable slope (Chae et al. 2015). In this study, the slope stability analysis was conducted using the observed slip surface by manual analysis. Firstly, the manual analysis was conducted by dividing the mass of failure into 30 slices (Figure 22). Specifying the number of slices higher than 30 slices seldom changes the safety factor significantly (GEOSLOPE 2012). The critical safety factor of the slope is strongly dependent on the shear strength parameters that are physically and analytically related to the soil parameters $(\gamma, c$, and $\phi)$ (Erzin and Cetin 2012). The unit volume weight $(\gamma)$ of $14.77 \mathrm{kN} / \mathrm{m}^{3}$ was set to be constant 
according to the site investigation. The cohesion $(c)$ and friction angle $(\phi)$ are set to be arbitrary and trial values. However, the trial values of shear strength properties ( $c$ and $\phi$ ) can be predicted by using the actual single slip surface (Wesley and Leelaratnam 2001). Thus, by changing the cohesion (c) and friction angle $(\phi)$ values and using the observed slip surface, the critical values of the safety factor can be determined. Through our calculations, four sets of the cohesion $(c)$ and friction angle $(\phi)$ values were obtained as shown in Table 4.

The combination of shear strength parameters from the manual analysis must be verified to get the actual shear strength parameters when the failure happens. Therefore, slope stability analysis was re-conducted by using the limit equilibrium software SLOPE/W module of GeoStudio 2020 student version (Abbas and Mutiny 2018). The SLOPE/W simulation produces a critical slip surface and new safety factor for each combination of shear strength parameters. The critical slip surface in slope stability analysis is the slip surface that produces the minimum factor of safety in the static analysis (Sarma and Tan 2006). The geometry of the slope used for the simulation is shown in Figure 23. A colluvial soil layer, bedrock and measured ground surface before slope failure were applied. The debris flow soil and the weathered rock was assumed as bedrock since the SPT N-value is 50 at a depth $3.3 \mathrm{~m}$ on SPT-1 and at a depth $6 \mathrm{~m}$ on SPT-2 (see Figures 13 and 14). Furthermore, the shear strength parameters from the manual analysis (see, Table 4) were used in SLOPE/W as the material of the soil. The SLOPE/W provides an entry and exit method to define the critical slip surface (GEOSLOPE 2012). Therefore, the area around the crown of slope failure is specified to be the entry of the slip surface. Meanwhile, the area around the toe of slope failure is defined as the exit of the slip surface. The area of the crown and toe of the slip surface can be obtained from the site investigation (Figures 22 and 23). Moreover, the entry and exit area of the slip surface was divided into 21 points (Figure 23). The total trial slip surfaces of 2205 are created by connecting each point along the entry area with the exit area. First, SLOPE/W connects a point along the entry area with a point along the exit area to make a connecting line. At the mid-point of this connecting line, SLOPE/W creates a perpendicular line. The perpendicular line is divided into several radius points. The radius point with the entry and exit points are used to form a circle as a slip surface (GEOSLOPE 2012). For example, 5 slip surfaces are created between entry point number 21 and exit point number 1 with 5 radius points along the perpendicular line as shown in Figure 24. This approach was repeated for all the combinations with 21 different entry and exit points. Furthermore, SLOPE/W calculated safety factor for each trial slip surfaces to obtain the lowest safety factor at the critical slip surface.

Figure 25 shows the critical slip surface for each combination of shear strength parameters and the observed slip surface, and the comparison results between the manual analysis and SLOPE/W calculations are shown in Table 4. Based on Figure 25 and Table 4, when the friction angle is $31^{\circ}$ and cohesion is $4.62 \mathrm{kN} / \mathrm{m}^{2}$, the critical slip surface coincides with the observed slip surface, and the safety factor estimated by SLOPE/W is 1 . Moreover, the estimated shear strength parameters from back analysis must be verified with shear strength parameters which are obtained from laboratory tests for colluvial soil. Jeng and Sue (2015) conducted a direct shear test to obtain the shear strength parameters for colluvial soil. Their results showed the average value of cohesion (c) and friction angle $(\phi)$ for colluvial soil is $18.5 \mathrm{kPa}$ and $29.6^{\circ}$, respectively. However, the standard deviation of the cohesion value was calculated to be 12.04 . Although the friction angle $(\phi)$ from the back analysis and laboratory test were not much different, the cohesion value for colluvial soils is significantly different. The significant difference in cohesion value was caused by the high standard deviation of cohesion values which is obtained from laboratory tests. The high standard deviation of cohesion value may be caused by the different weathering degrees and 
lithological components, causing different grain size distribution and mechanic characteristics (Jeng and Sue 2015). Therefore, the prediction with the estimated shear strength parameters (i.e., $\phi=31^{\circ}$ and $c=4.62 \mathrm{kN} / \mathrm{m}^{2}$ ) may be the most plausible scenario to represent the observed slope failure.

\section{Conclusions}

A tilt sensor is one type of simple equipment for observing slope movement. Recently, most tilt sensors require the use of conventional technology, such as cables and electricity. Slope monitoring system using tilt sensors combined with Low Power Wide Area (LPWA) network technology has been developed. The tilt sensors were easily set up inside the box by simply staking a pile without wiring or cables, and the box was set on piles (Figure 8). This system can be used over any wide area or surface by employing not only one tool, but multiple boxes and piles. The measurement results are transmitted to the receiver and can be viewed through computers and Smartphones. After the installation is completed, the monitoring system can be started immediately. Moreover, the costs are lower compared to those of conventional technology.

In this study, radio wave propagation tests were conducted to evaluate the communication performance of LPWA and to determine the best location for the receiver and the transmitter. Based on the results, it was possible to receive radio waves only from Location 4 . Therefore, a radio wave propagation experiment was carried out by installing a receiver at Location 4.

Since the monitoring system was installed, the measured data have been recorded. During the monitoring, heavy rain occurred in East Japan in July 2018. At that time, the data from two sensors increased rapidly. One of the sensors, Sensor H, stopped working 7 hours after the rapid increase began. Several tests, such as site surveys, field tests, and back analyses, were conducted to gain a better understanding of the slope failure mechanism. From the back analysis, the cohesion and friction angle when slope failure happened maybe $4.62 \mathrm{kN} / \mathrm{m}^{2}$ and $31^{\circ}$, respectively.

The developed system using sensors and LPWA has been continued to monitor the movement of targeted slope. This system could grasp slope deformation during heavy rain. However, the collection of additional data and upgrading the system will be required to increase the reliability of the system.

\section{Acknowledgments}

This research was supported by the Ministry of Land, Infrastructure, Transport and Tourism Shikoku Regional Development Bureau, the SECOM Science and Technology Foundation, the Shikoku Create Association, and the Kurata Grants of the Hitachi Global Foundation. Their support is gratefully acknowledged. The data used in this work are available from the authors upon request.

\section{References}

Abbas JM, Mutiny ZA (2018) Slope stability analysis for earth dams using (Geo-Slope/W). Diyala J Eng Sci 11:70-81. https://doi.org/10.26367/DJES/VOL.11/NO.1/12

Adelantado F, Vilajosana X, Tuset PP, Martinez B, Melia SJ, Watteyne T (2017) Understanding the limits of 
LoRaWAN. IEEE Commun Mag 55:34-40. https://doi.org/10.1109/MCOM.2017.1600613

Ali AA, Yanglin G, Zifan C (2017) Study of hall effect sensor and varitey of temperature related sensitivity. J Eng Technol Sci. 49: 308-321. https://doi.org/10.5614/j.eng.technol.sci.2017.49.3.2

Ali M (2014) Correction of temperature and acceleration effects on MEMS gyro output signals. Thesis, Middle East Technical University

Augustin A, Yi J, Clausen T, Townsley WM (2016) A study of Lora: Long range \& low power networks for the internet of things. Sens 16:1-18. https://doi.org/10.3390/s16091466

Bowles J (1996) Foundation analysis and design. McGrow-Hill Companies, Singapore

Burman A, Acharya SP, Sahay RR, Maity D (2015) A comparative study of slope stability analysis using traditional limit equilibrium method and finite element method. Asian J Civ Eng 16: 467-492

Chae BG, Lee JH, Park HJ, Choi J (2015) A method for predicting the factor of safety of an infinite slope based on the depth ratio of the wetting front induced by rainfall infiltration. Nat Hazards Earth Syst Sci 15:18351849. https://doi.org/10.5194/nhess-15-1835-2015

Erzin Y, Cetin T (2012) The use of neural networks for the prediction of the critical factor of safety of an artificial slope subjected to earthquake forces. Scientia Iranica 19:188-194. https://doi.org/10.1016/j.scient.2012.02.008.

Feng W, Dong M, Zhangsui X (2007) A research aboth the temperature compensation of hall sensor. 8th International Conference on Electronic Measurement and Instrum. 4:131-134. https://doi.org/ 10.1109/ICEMI.2007.4351100.

GEOSLOPE (2012) Stability modeling with Slope/W. GEO-SLOPE International Ltd, Calgary

Ishtiwi MAY (2016) Correlation between the standard penetration test and the dynamic cone penetration test for sandy soil. Thesis, University of Tripoli

Jeng CJ, Sue DZ (2016) Characteristics of ground motion and threshold values for colluvium slope displacement induced by heavy rainfall: a case study in northern Taiwan. Nat. Hazards Earth Syst. Sci. 16: 1309-1321. doi:10.5194/nhess-16-1309-2016

Kane WF, Beck TJ (2001) Instrumentation practice for slope monitoring. Eng Geology Pract in Northen California $1-20$

Klimes J, Rowberry MD, Blahut J, Briestensky M, Hartvich F, Kostak B, Rybar J, Stemberk J, Stepancikova P (2011) The monitoring of slow-moving landslides and assessment of stabilitasation measures using an optical-mechanical crack gauge. Landslide. https://doi.org/10.1007/s10346-011-0306-4

Li B, Zhang F, Wang D (2018) Impact of crack on stability of slope with linearly increasing undrained strength. Mathematical Probl. in Eng. 1-11: https://doi.org/10.1155/2018/1096513

Lin H, Zhong W, Xiong W, Tang W (2014) Slope stability analysis using limit equilibrium method in nonlinear 
criterion. Scientific World J 1-7. https://doi.org/10.1155/2014/206062.

Mansour M, Samieh A, Deen ANE (2019) Use of lightweight dynamic cone penetrometer for compaction control of cohesionless soils. Internation J. Geomate. 17: 115-122. https://doi.org/10.21660/2019.64.82998

Mekki K, Bajic E, Chaxel F, Meyer F (2019) A comparative study of LPWAN technologies for large-scale IoT deployment. ICT Express 5:1-7. https://doi.org/10.1016/j.icte.2017.12.005

Ministry of Land, Infrastructure and Transport. (2018) Summary of sediment-related disasters caused by heavy rainfall in July 2018. Ministry of Land, Infrastructure and Transport web. https://www.mlit.go.jp/river/sabo/jirei/h30dosha/H30_07gouu_gaiyou1807311800.pdf. Accessed 19 October 2020

Park BS, Cho H, Youn SP, Park DI (2016) Analysis and evaluation of stability for the reactivated landslide along deep-seated weakness zones. Geo-Eng. 7: 1-15. https://doi.org/10.1186/s40703-016-0016-9

Qiao S, Feng C, Yu P, Tan J, Uchimura T, Wang L, Tang J, Shen Q, Xie J (2020) Investigation on surface tilting in the failure process of shallow landslides. Sens. 20:1-29. https://doi.org/10.3390/s20092662

Qureshi UM, Shaikh FK, Aziz Z, Shah SYMZ, Sheikh AA, Felemban E, Qaisar SB (2016) RF path and absorption loss estimation for underwater wireless sensor networks in different water environments. Sens. 16: 1-15. https://doi.org/10.3390/s16060890.

Rabie M (2014) Comparison study between traditional and finite element methods for slopes under heavy rainfall. HBRC J 10:160-168. https://doi.org/10.1016/j.hbrcj.2013.10.002.

Ramesh MV (2014) Design, development, and deployment of a wireless sensor network for detection of landslides. Ad Hoc Netw 13:2-18. https://doi.org/10.1016/j.adhoc.2012.09.002

Robert LY, Jihu Z, Vitton S (1997) Determination of interslice force in slope stabililty analysis. Soil Found 37:6572

Sarma SK, Tan D (2006) Determination of critical slip surface in slope analysis. Geotechnique 56:539-550. https://doi.org/10.1680/geot.2006.56.8.539

Sinha RS, Wei Y, Hwang SH (2017) A survey on LPWA technology: LoRa and NB-IoT. ICT Express 3:14-21. https://doi.org/10.1016/j.icte.2017.03.004

Song Y, Lin J, Tang M, Dong S (2017) An internet of energy things based on wireless LPWAN. Eng 3: 460-466. https://doi.org/10.1016/J.ENG.2017.04.011

Tarawneh B (2017) Predicting standard penetration test N-value from cone penetration test data using artificial neural networks. Geosci Frontiers 8:199-204. https://doi.org/10.1016/j.gsf.2016.02.003

Uchimura T, Towhata I, Wang L, Nishie S, Yamaguchi H, Seko I, Qiao J (2015) Precaution and early warning of surface failure of slopes using tilt sensors. Soils Found 55:1086-1099. https://doi.org/10.1016/j.sandf.2015.09.010 
Varnes DJ (1978) Slope movement and types and processes. In: Landslides: analysis and control. Special Report 176: 12-33

Wesley LD, Leeratnam V (2001) Shear strength parameters from back-analysis of single slips. Geotechnique 51:373-374. https://doi.org/10.1680/geot.51.4.373.39399

Xie J, Uchimura T, Wang G, Shen Q, Maqsood Z, Xie C, Liu J, Lei W, Tao S, Chen P, Dong H, Mei G, Qiao S (2019) A new prediction method for the occurrence of landslides based on the time history of tilting of the slope surface. Landslide. https://doi.org/10.1007/s10346-019-01283-8

Xie J, Uchimura T, Chen P, Liu J, Xie C, Shen Q (2019) A relationship between displacement and tilting angle of the slope suface inshallow landslides. Landslide. https://doi.org/10.1007/s10346-019-01135-5

Yang H, Wang F, Vilimek V, Araiba K, Asano S (2015) Investigation of rainfall-induced shallow landslides on the northeastern rim of Aso caldera, Japan, in July 2012. Geoenvironmental Disasters 2:1-14. https://doi.org/10.1186/s40677-015-0028-3.

Yusof NQ, Zabidi H (2018) Reliability of Using Standard Penetration Test (SPT) in Predicting Properties of Soil. J Phys 1082:1-6. https://oi.org/10.1088/1742-6596/1082/1/012094 


\section{Figure Captions}

Fig. 1 Scheme of monitoring system with LPWA and tilt sensors

Fig. 2 Arduino Uno as transmitter

Fig. 3 Results of radio wave experiments for choosing location of gateway device

Fig. 4 Schematic of observation site and sensor locations

Fig. 5 Positions for gateway device

Fig. 6 Strength of radio waves received from observation sites

Fig. 7 Locations of slope monitoring in Tateyama area

Fig. 8 Installation at monitoring slope

Fig. 9 Monitoring system from homepage view

Fig. 10 Correlation between temperature and tilt sensor data

Fig. 11 The tilt sensor data with temperature compensation and moving average filter

Fig. 12 Observation site before and after failure occurred

Fig. 13 Failure measurement and locations of field tests and samples for laboratory tests

Fig. 14 Standard penetration test results

Fig. 15 Cross-section of observation site

Fig. 16 Dynamic cone penetration test

Fig. 17 Dynamic cone penetration test results

Fig. 18 Slope model based on DCPT tests

Fig. 19 Particle size distribution results

Fig. 20 Tilt sensor and rainfall data from $5^{\text {th }}$ July $-8^{\text {th }}$ July 2018

Fig. 21 Observation of groundwater level during heavy rainfall

Fig. 22 The observed slip surface from site investigation

Fig. 23 Geometry of the slope for the SLOPE/W simulation

Fig. 24 The trial slip surfaces between entry point no.21 and exit point no.1

Fig. 25 Critical slip surface from each shear strength parameter and observed slip surface 


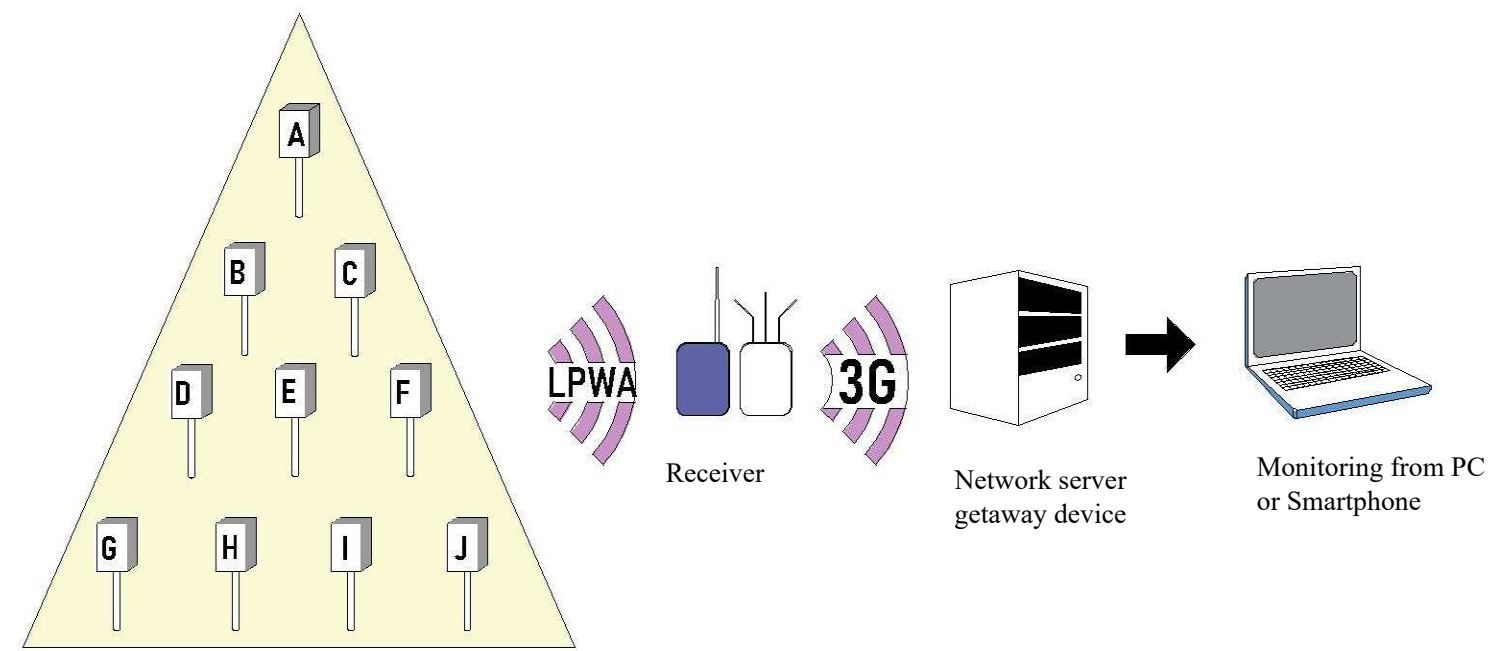

Site area installed with tilt sensors and LPWA devices

Fig. 1 Scheme of monitoring system with LPWA and tilt sensors 


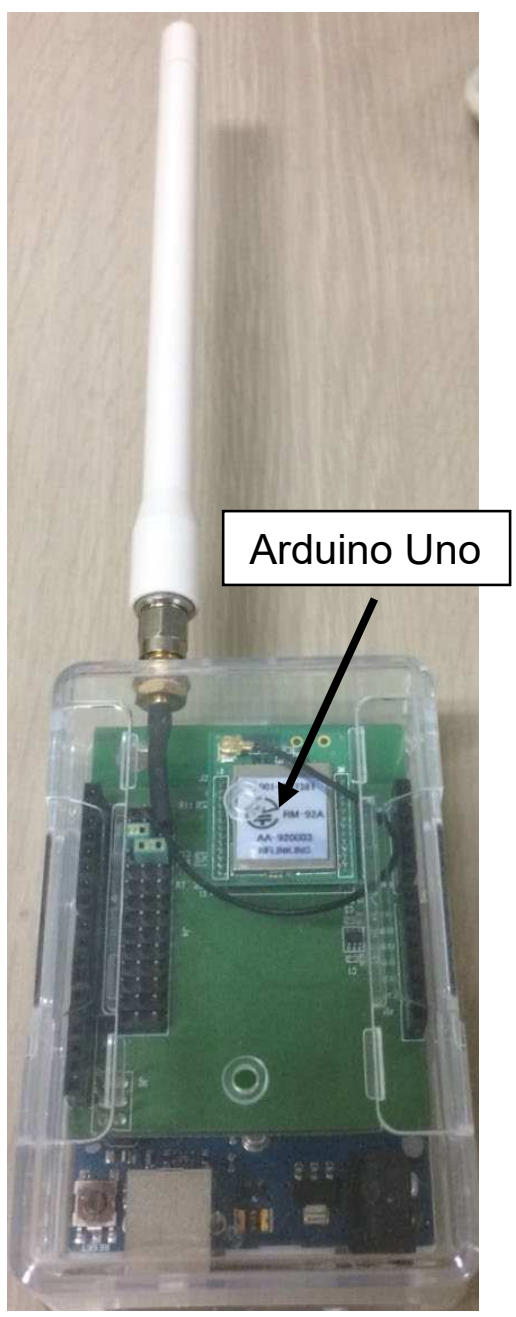

Fig. 2 Arduino Uno as transmitter 


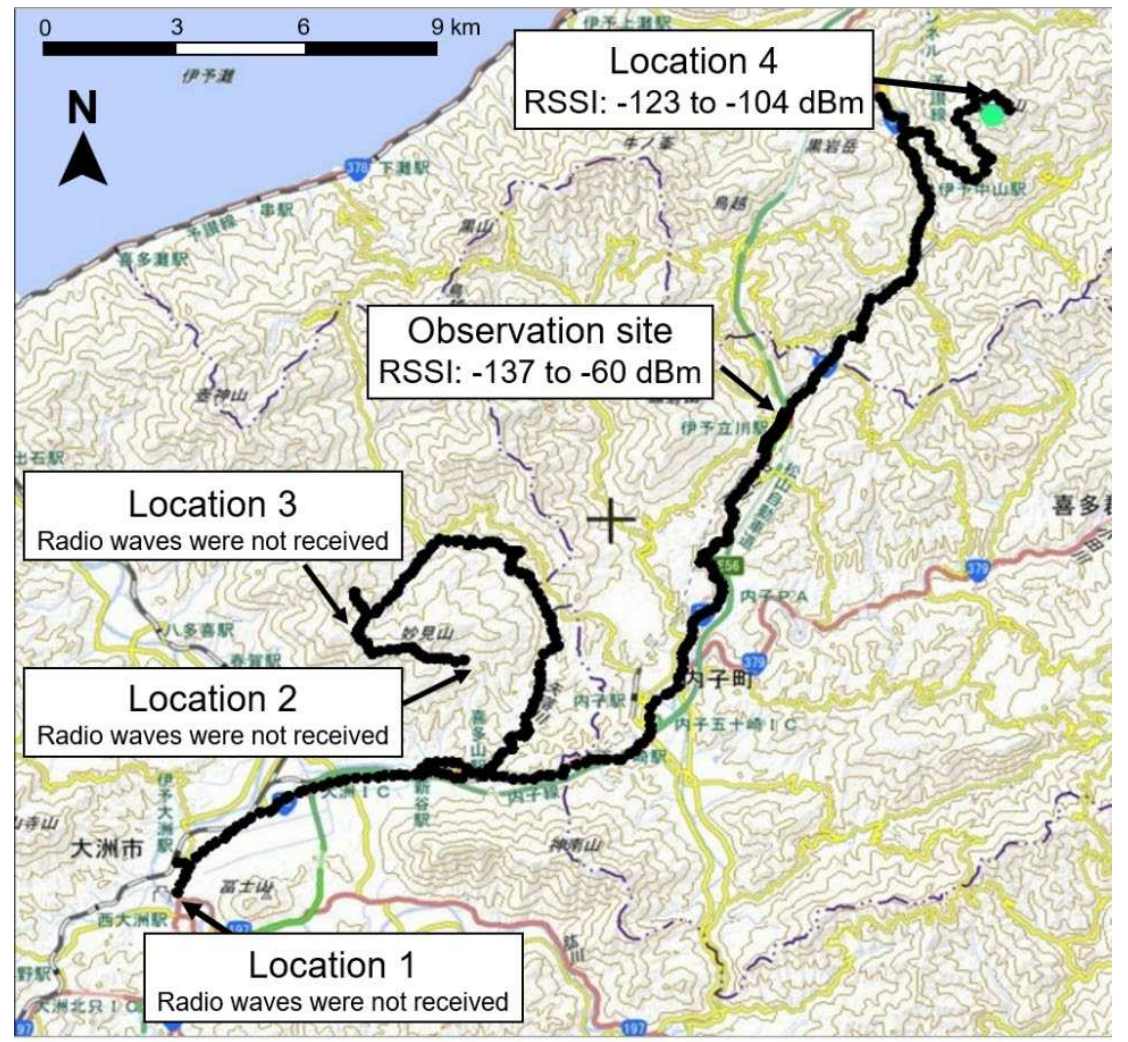

Fig. 3 Results of radio wave experiments for choosing location of gateway device 


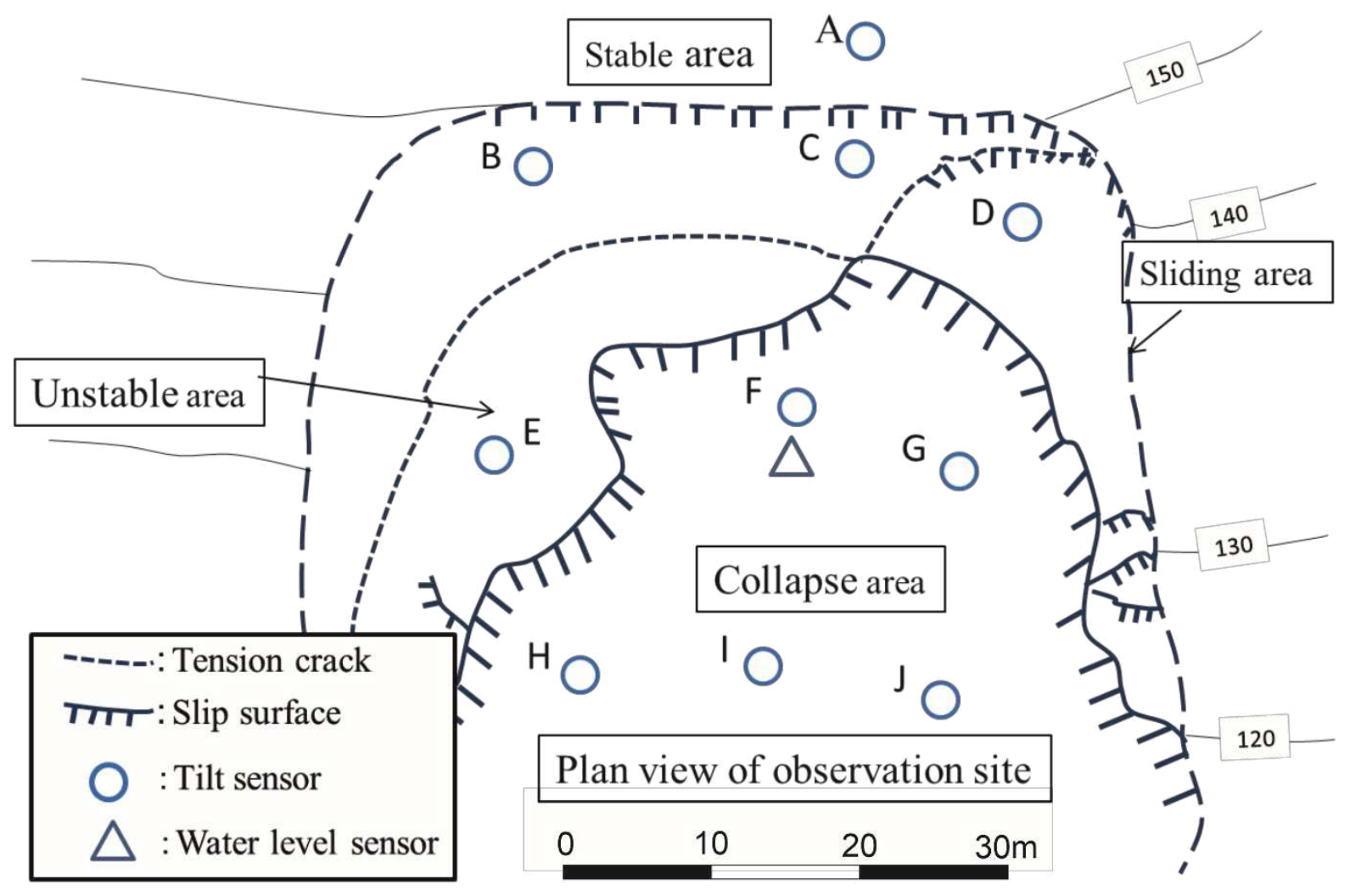

Fig. 4 Schematic of observation site and sensor locations 

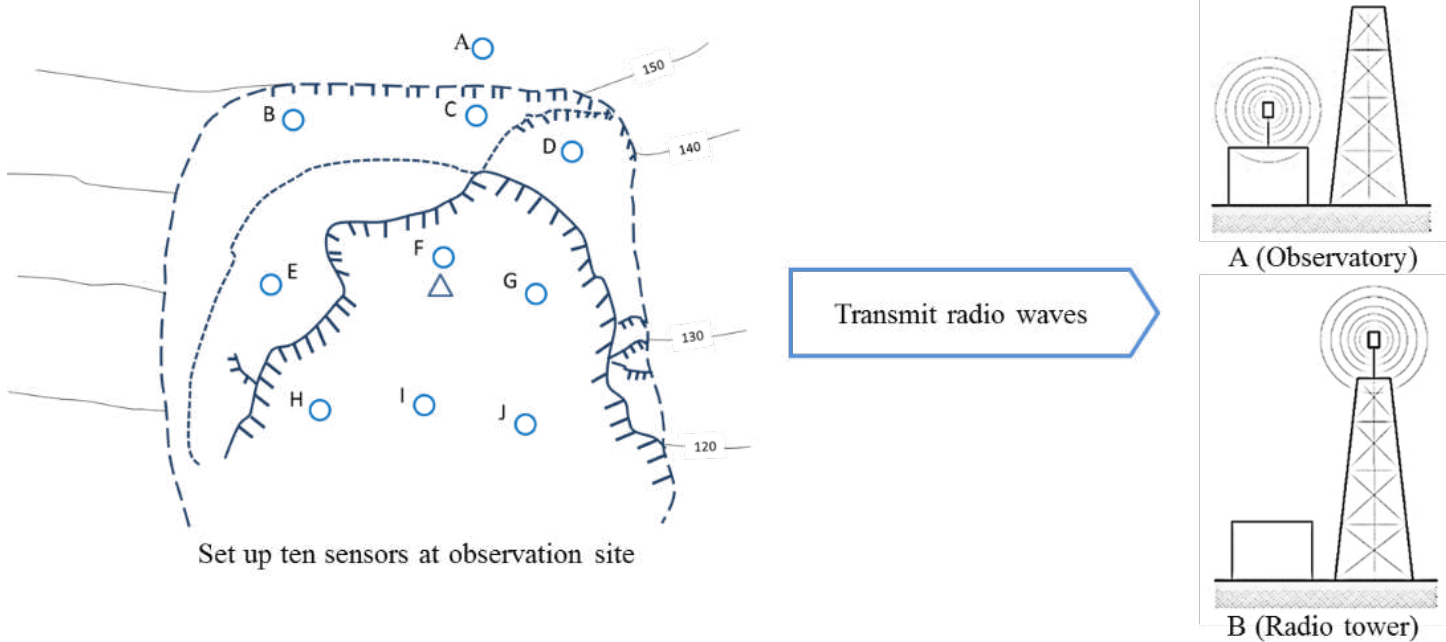

Fig. 5 Positions for gateway device 


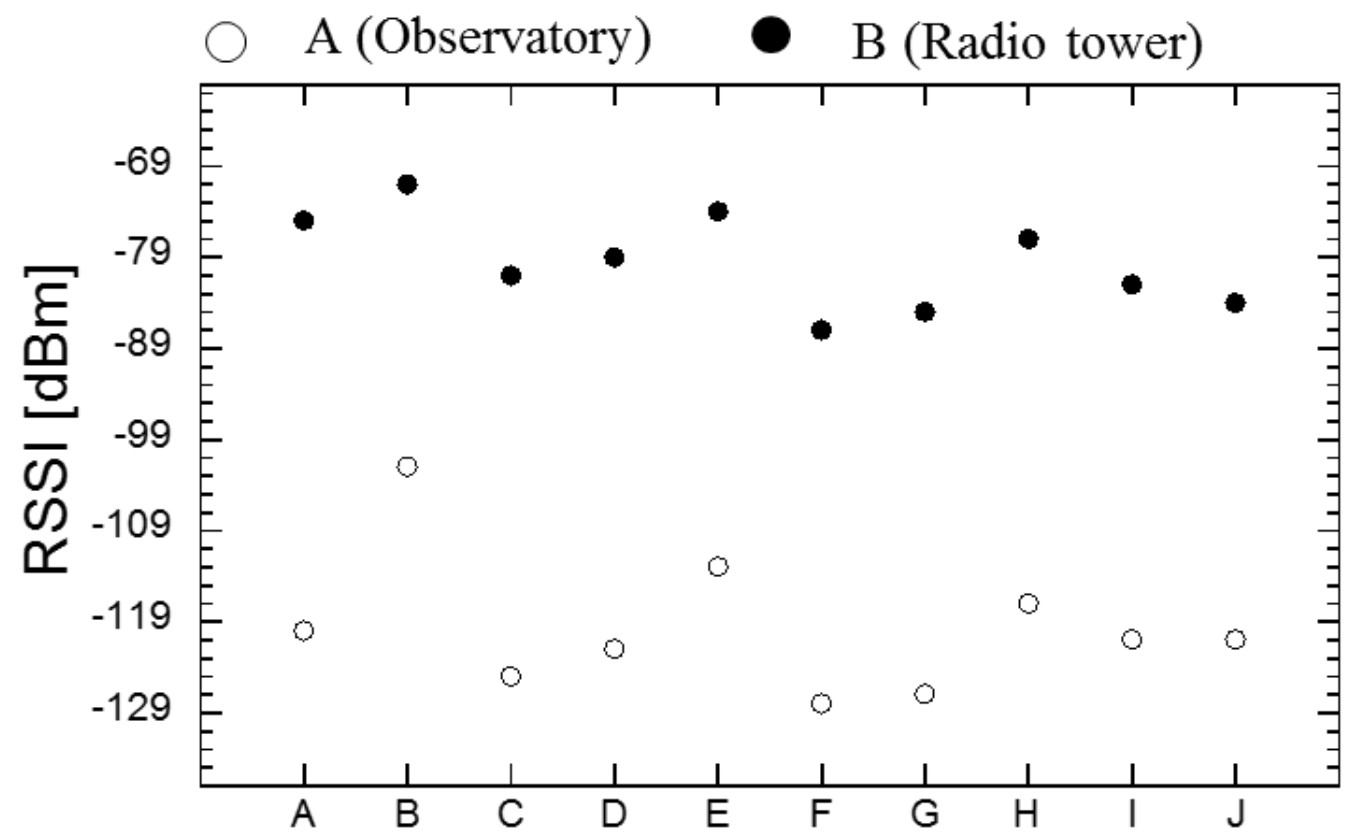

Fig. 6 Strength of radio waves received from observation sites 


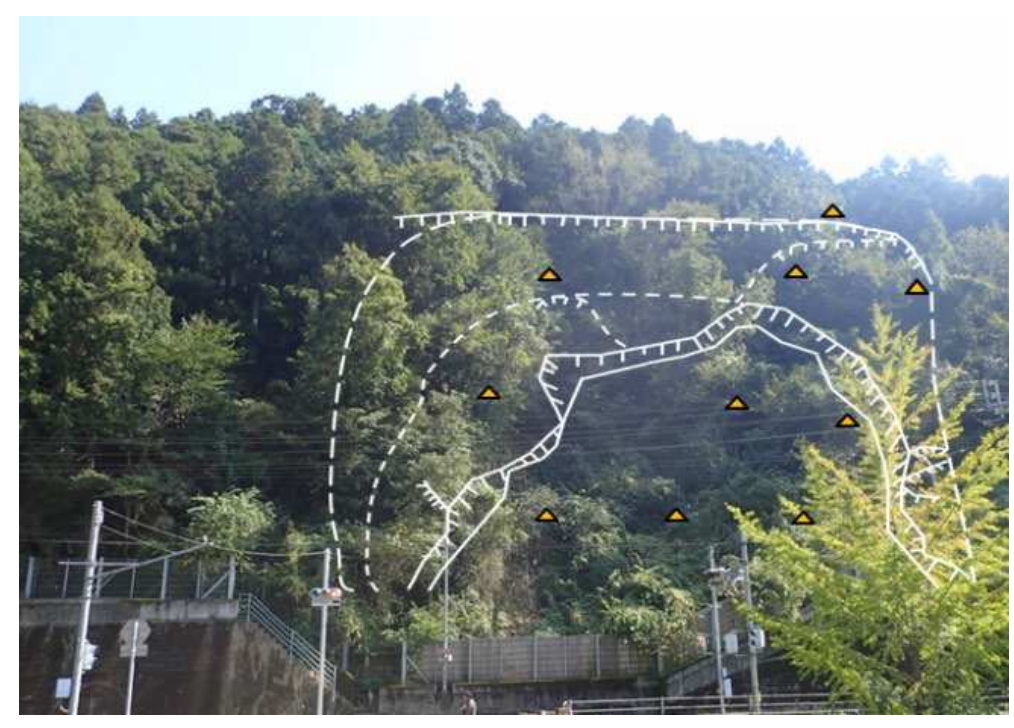

Fig. 7 Locations of slope monitoring in Tachiyama area 

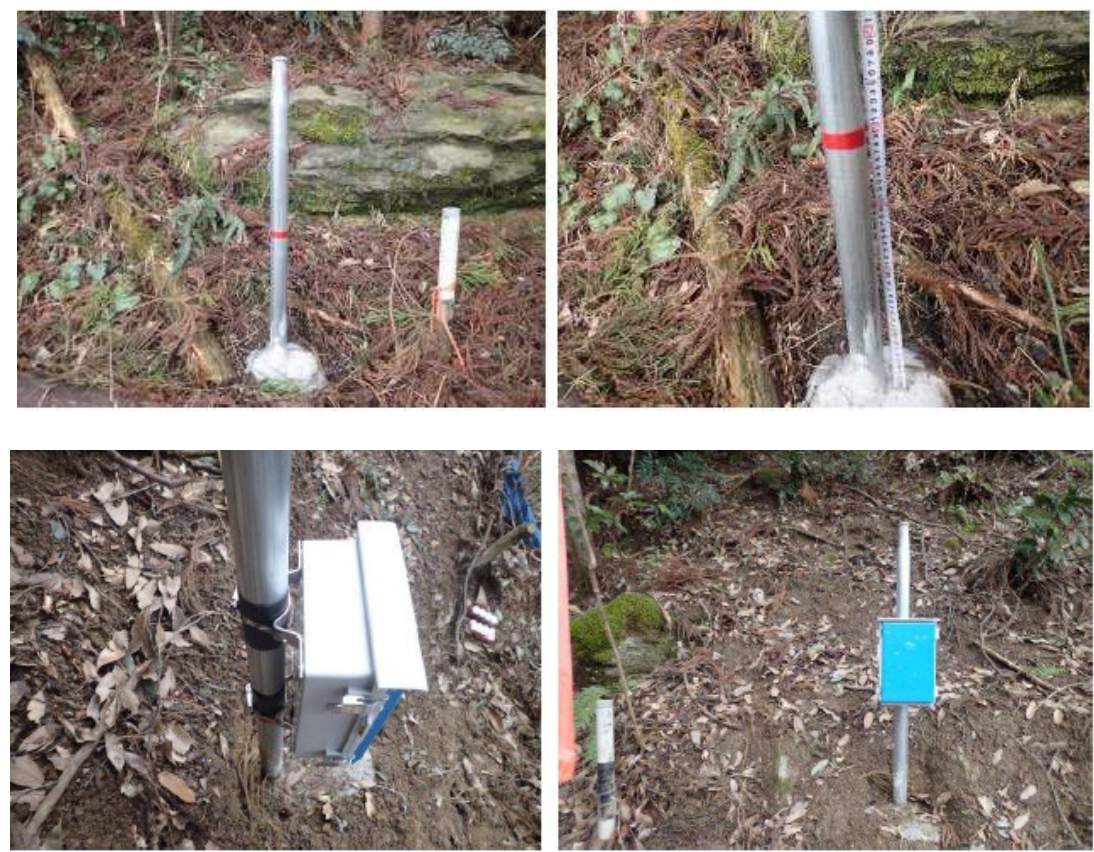

Fig. 8 Installation at monitoring slope 
Tachiyama area view plan

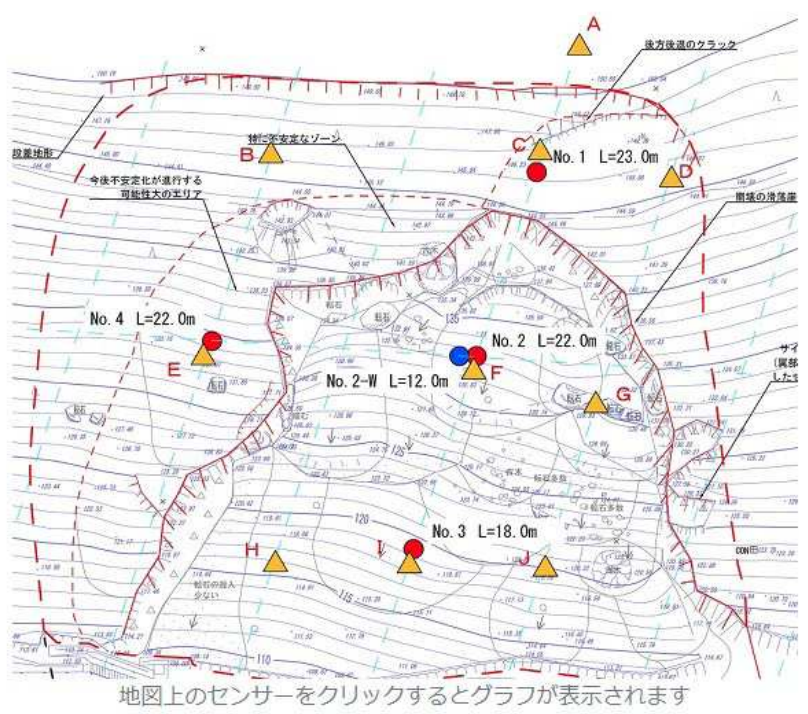

lyo,JP

ริ่า: $24.97{ }^{\circ} \mathrm{C}$

Clouds

\section{Last update}

\begin{tabular}{|cccccc} 
Sensor Name & Inclination Temperature & $\begin{array}{c}\text { Water } \\
\text { Level }\end{array}$ & Battery & Update \\
Slope-A & -0.05 & 23.25 & - & $95 \%$ & $14: 04: 42$ \\
\hline Slope-B & +0.09 & 23.75 & - & $44 \%$ & $14: 03: 54$ \\
\hline Slope-C & +0.03 & 24.00 & - & $64 \%$ & $13: 58: 13$ \\
\hline Slope-D & +0.09 & 23.75 & - & $60 \%$ & $14: 03: 39$ \\
\hline Slope-E & +0.03 & 23.75 & - & $91 \%$ & $14: 01: 44$ \\
\hline Slope-F & +0.09 & 24.00 & 9.77 & $92 \%$ & $13: 58: 53$ \\
\hline Slope-G & +0.25 & 23.75 & - & $62 \%$ & $14: 04: 42$ \\
\hline Slope-H & +0.64 & 24.75 & - & $78 \%$ & $13: 58: 18$ \\
\hline Slope-1 & -0.12 & 26.00 & - & $84 \%$ & $14: 04: 56$ \\
Slope- & -0.13 & 23.75 & - & $62 \%$ & $13: 58: 22$
\end{tabular}

Fig. 9 Monitoring system from homepage view 


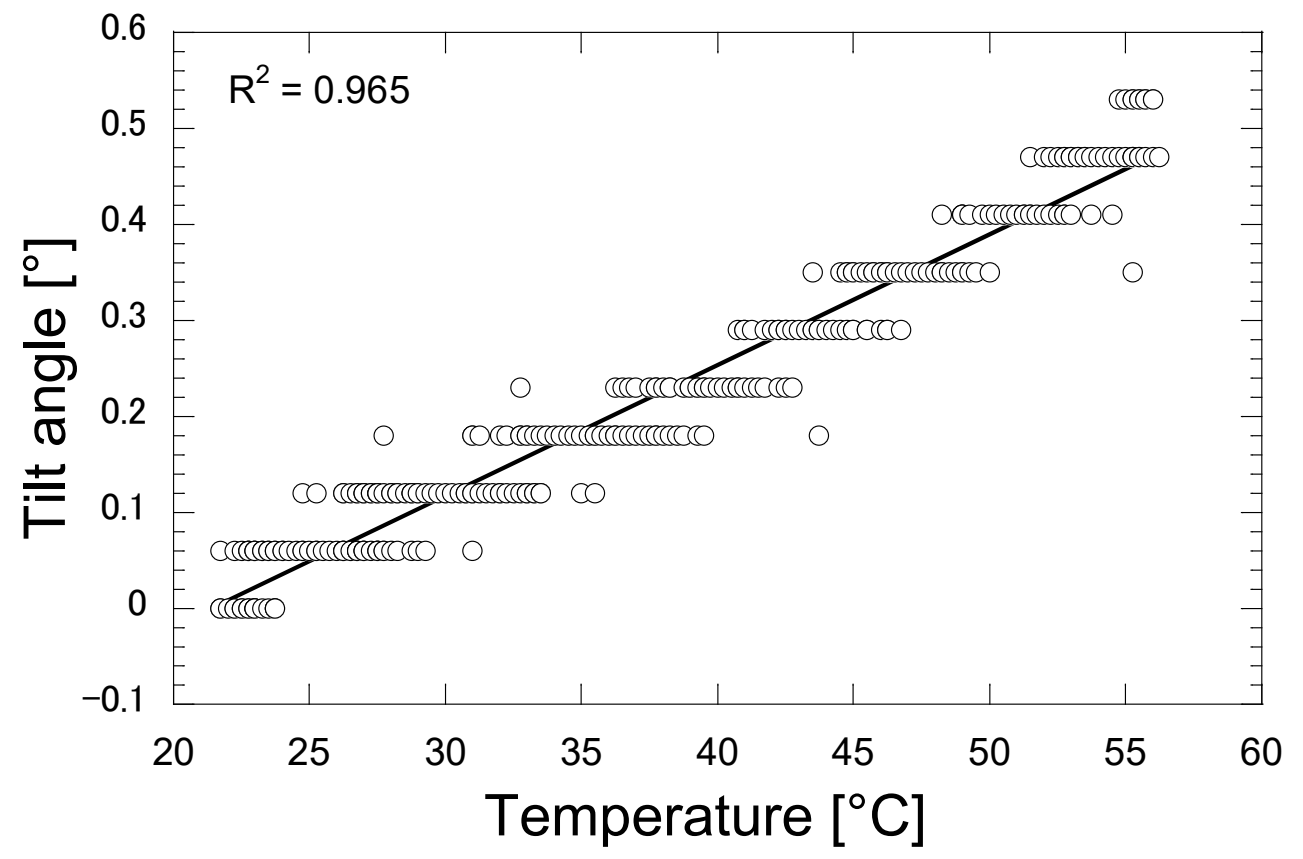

Fig. 10 Correlation between temperature and tilt sensor data 


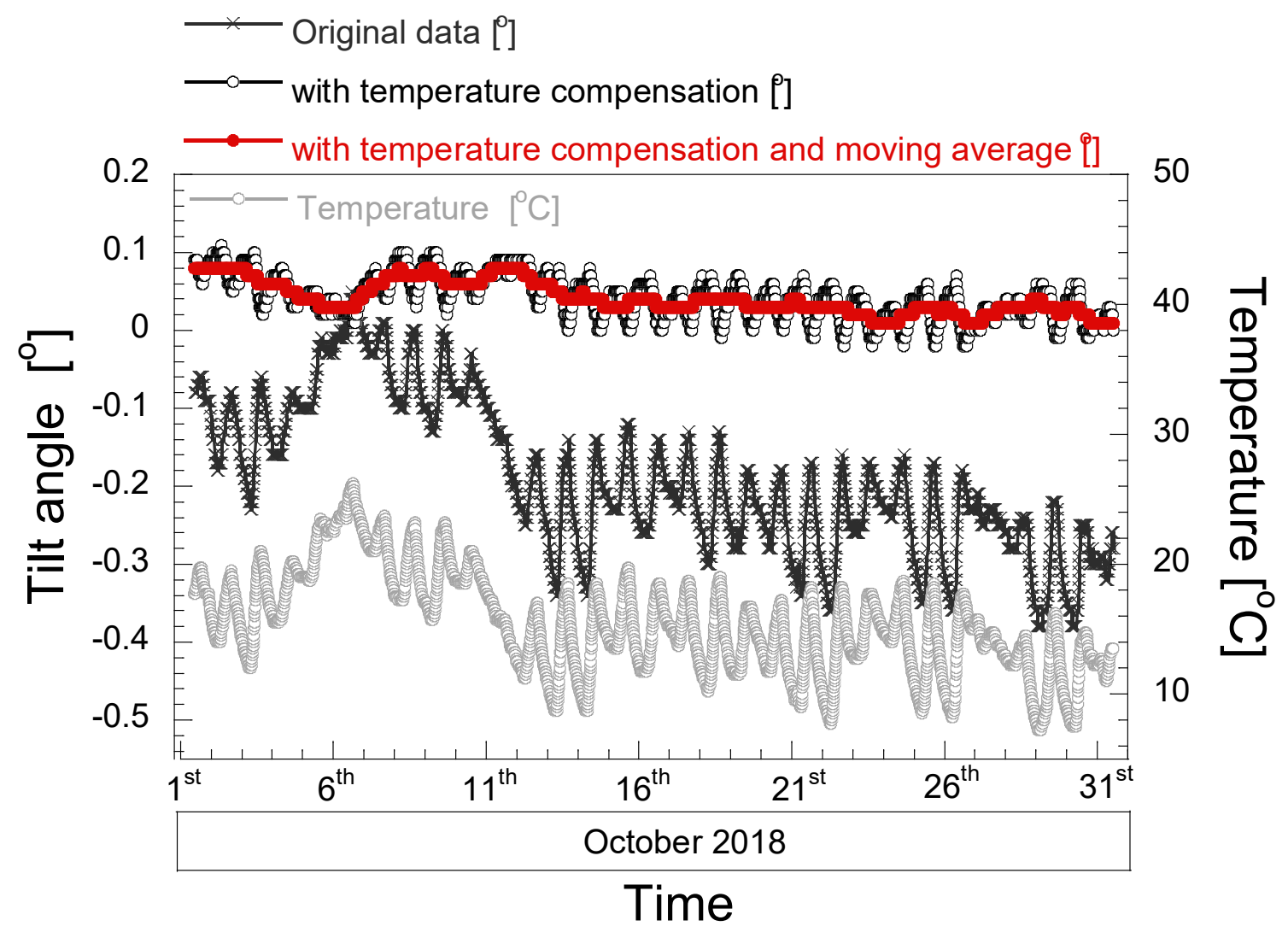

Fig. 11 The tilt sensor data with temperature compensation and moving average filter 


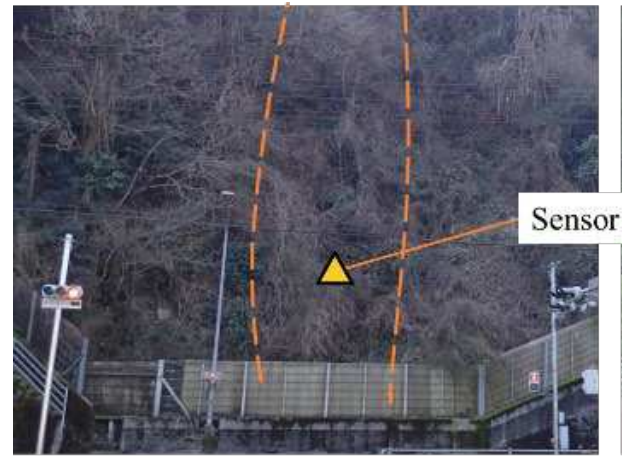

Monitoring site (March $1^{\text {st }}$ )

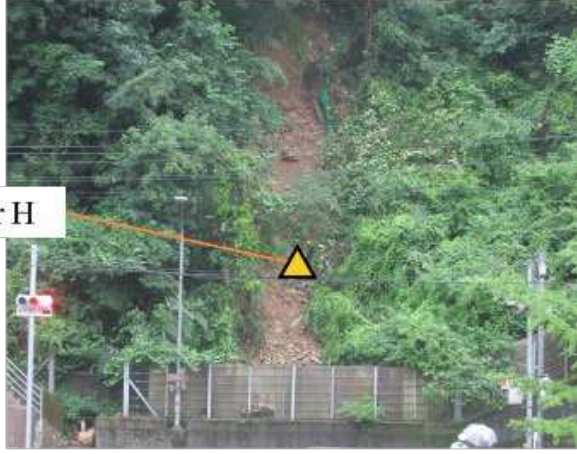

Monitoring site (July $7^{\text {th }}$ )

Fig. 12 Observation site before and after failure occurred 


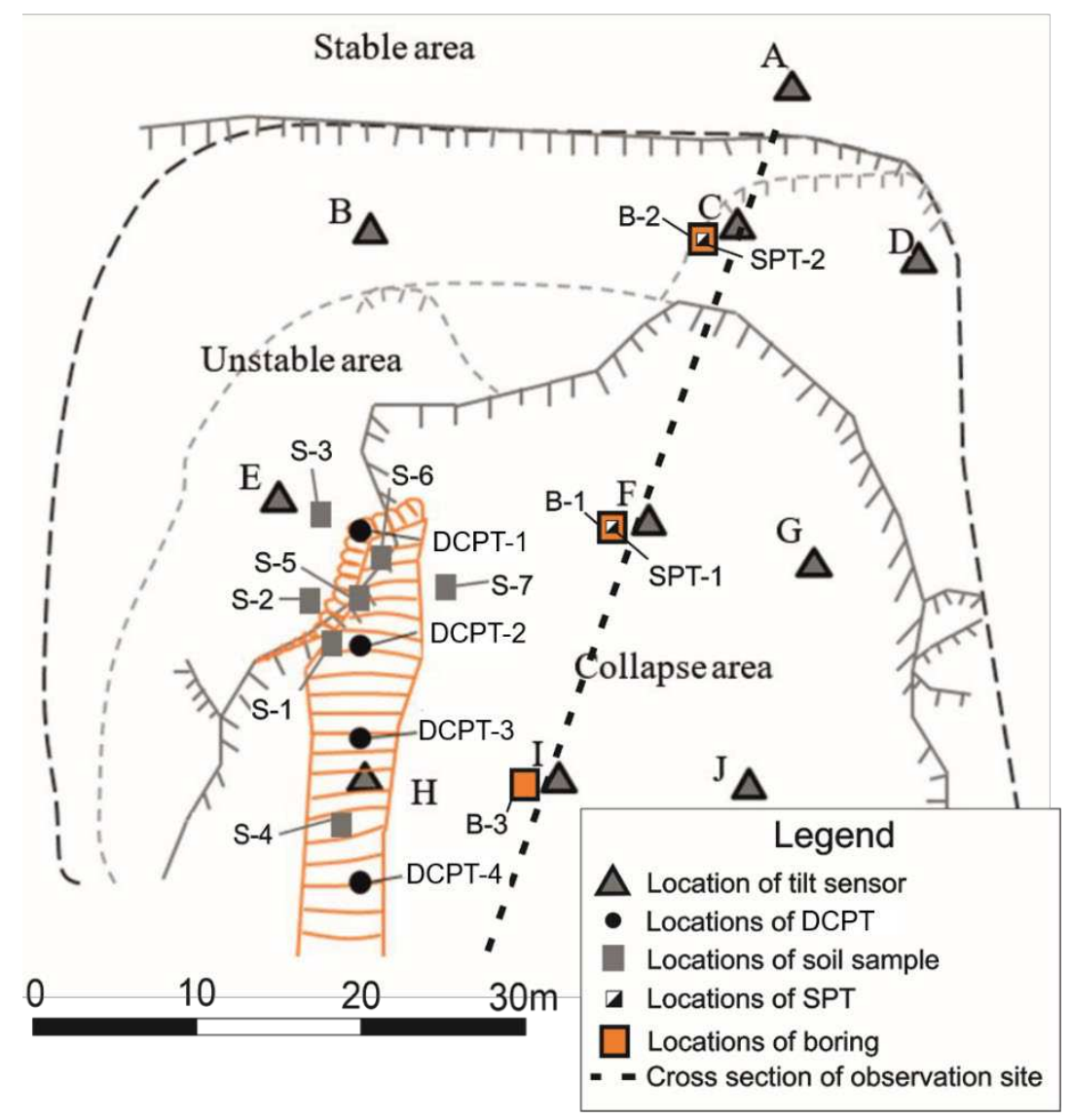

Fig. 13 Failure measurement and locations of field tests and samples for laboratory tests 

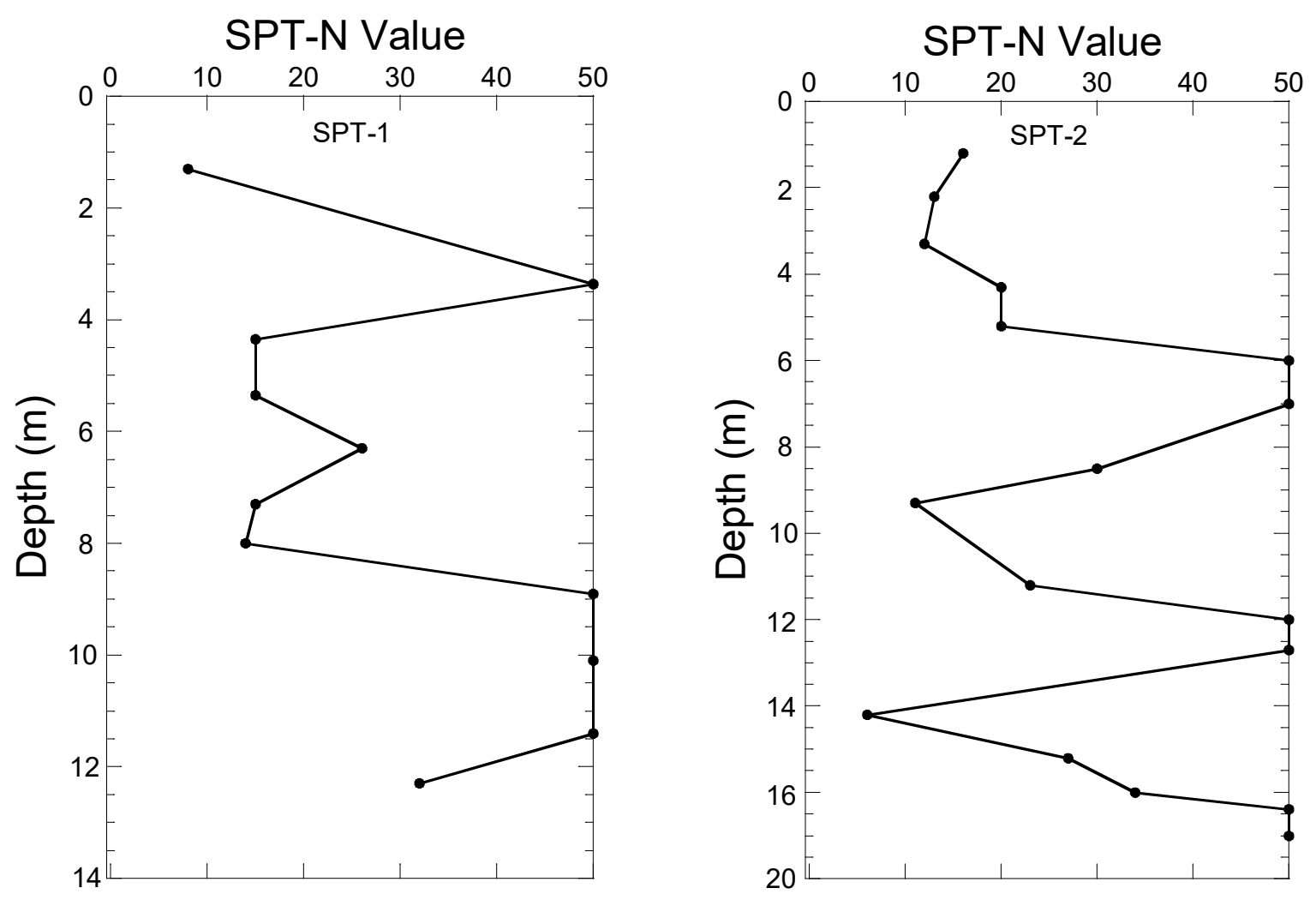

Fig. 14 Standard penetration test results 


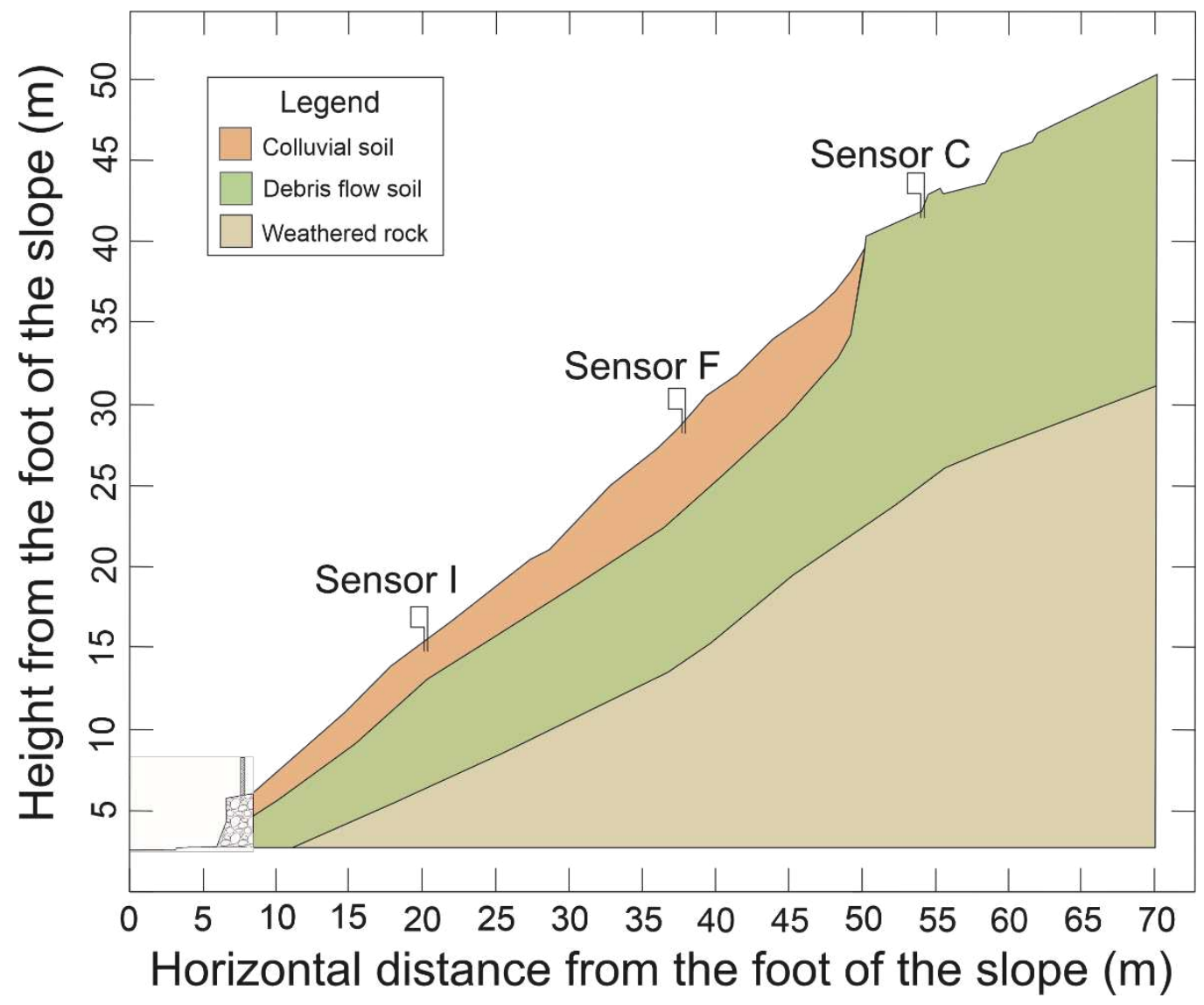

Fig. 15 Cross-section of the observation site 


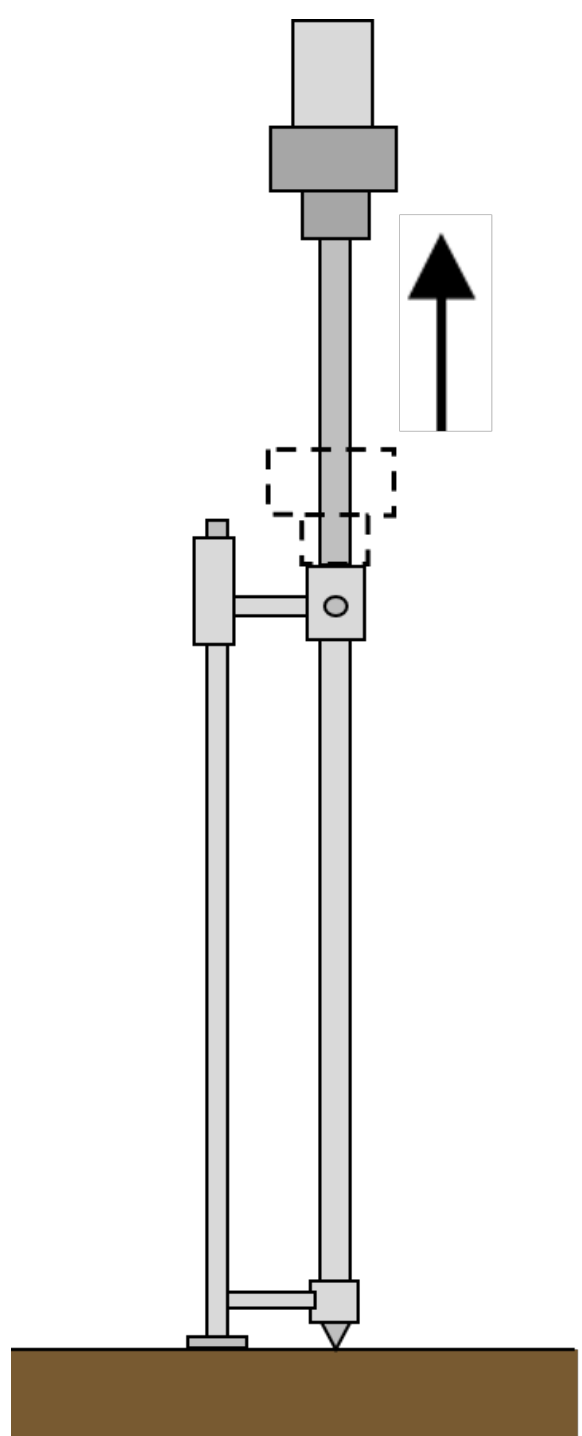

a. Before hammer dropping

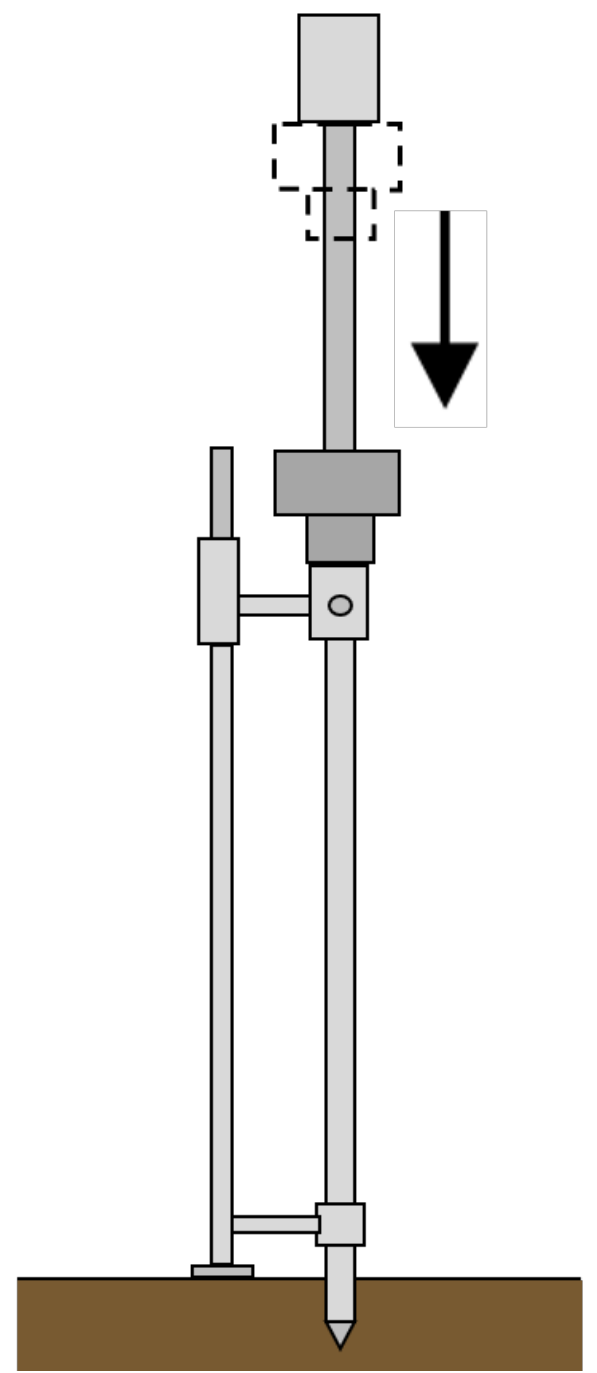

b. After hammer dropping

Fig 16. Dynamic cone penetration test 

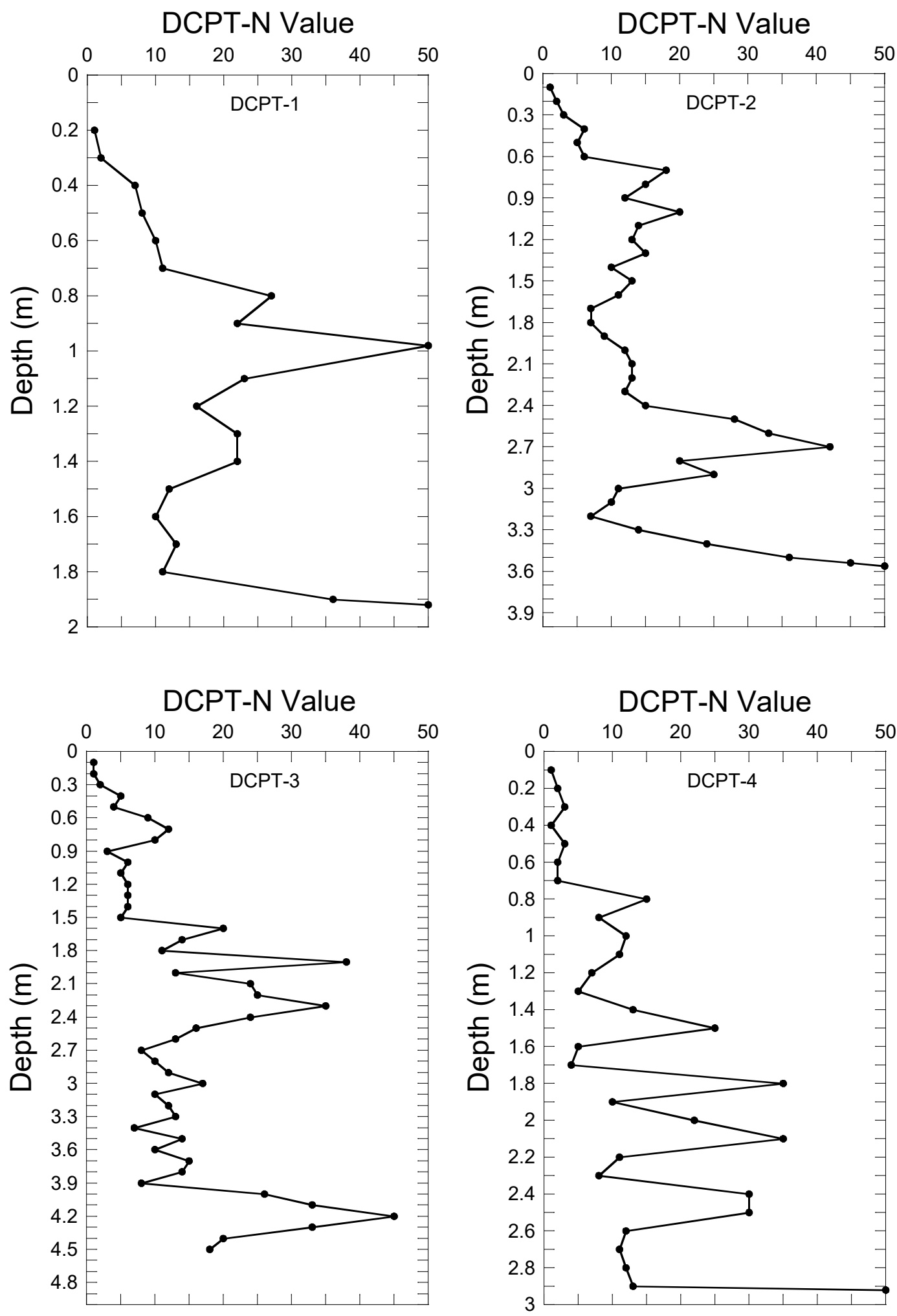

Fig. 17 Dynamic cone penetration test results 


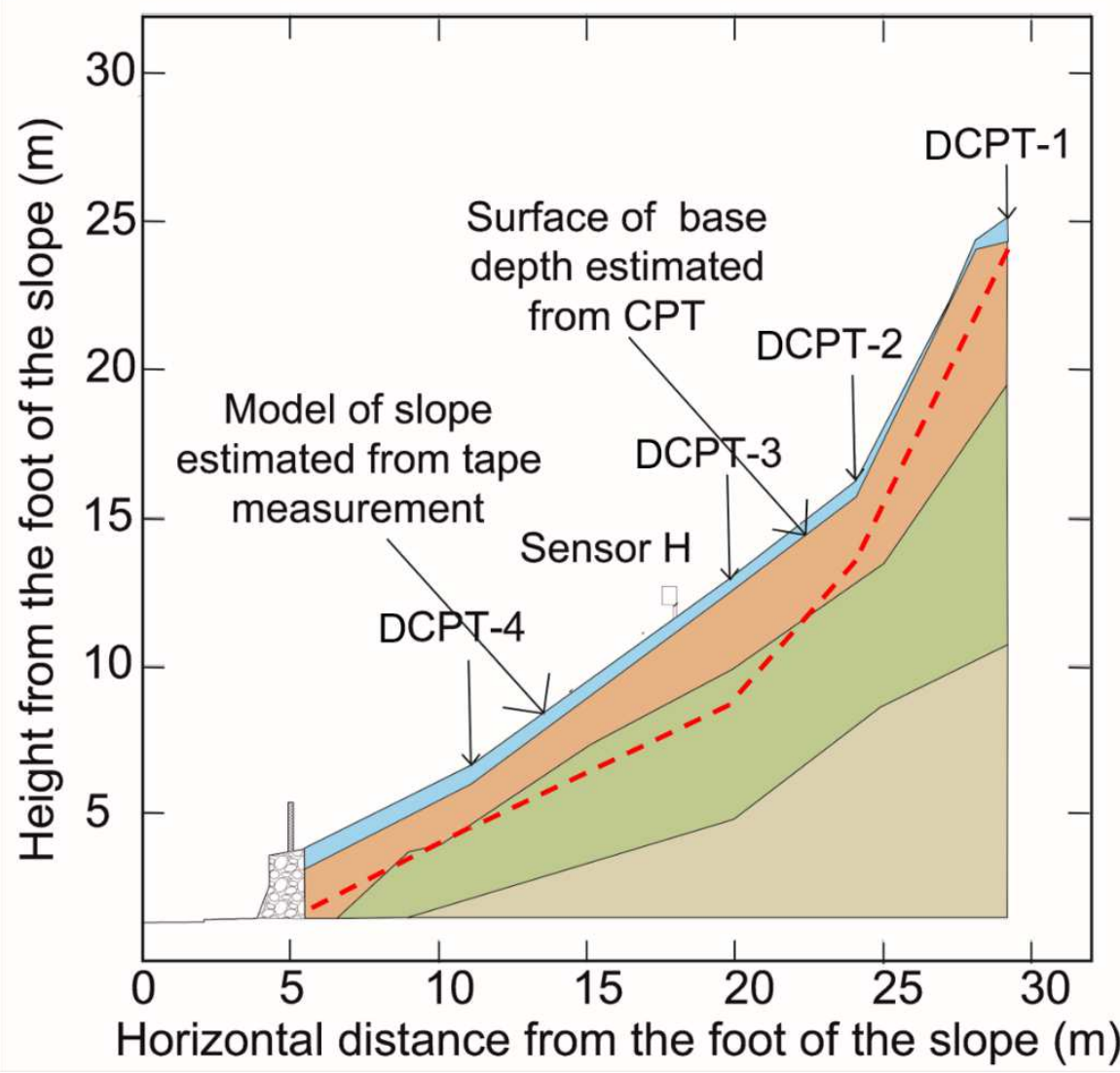

Fig. 18 Slope model based on tape measurement and DCPT tests 




Fig. 19 Particle size distribution results 


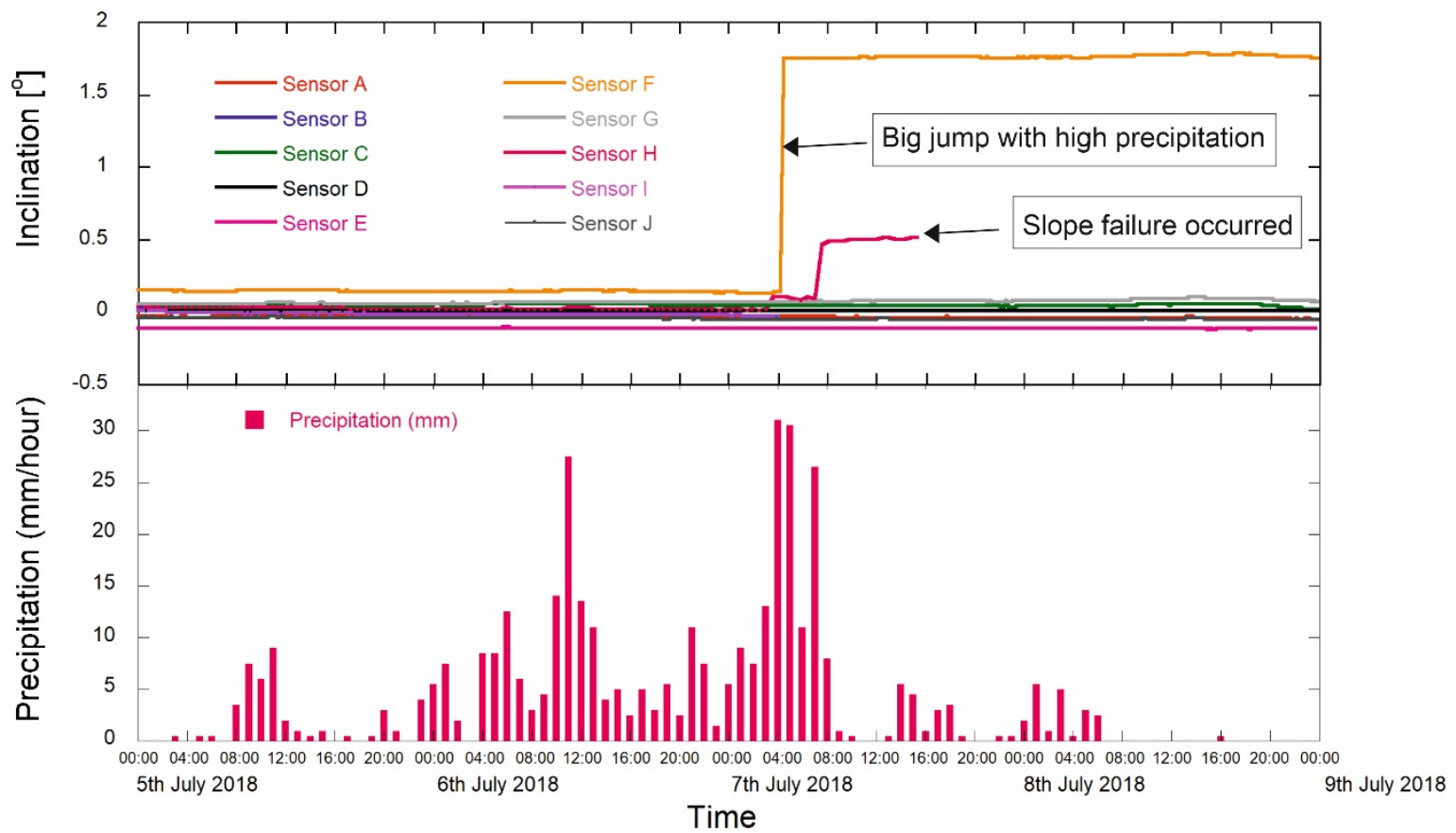

Fig. 20 Tilt sensor and rainfall data from $5^{\text {th }}$ July $-8^{\text {th }}$ July 2018 


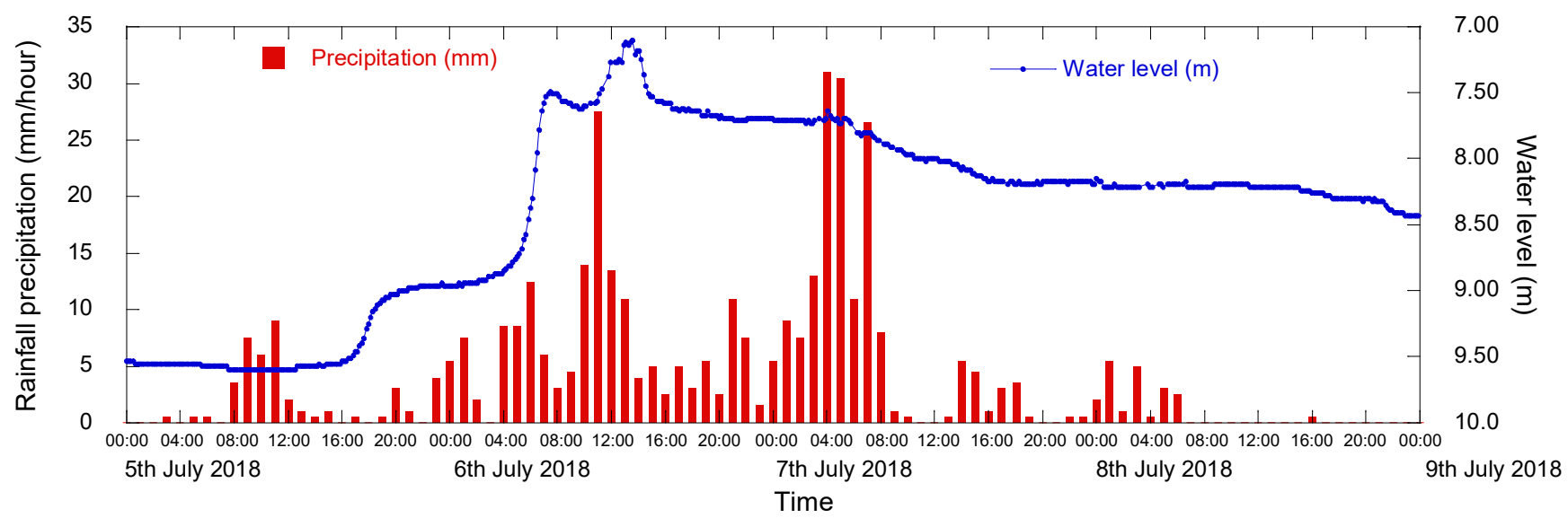

Fig. 21 Observation of groundwater level during heavy rainfall 


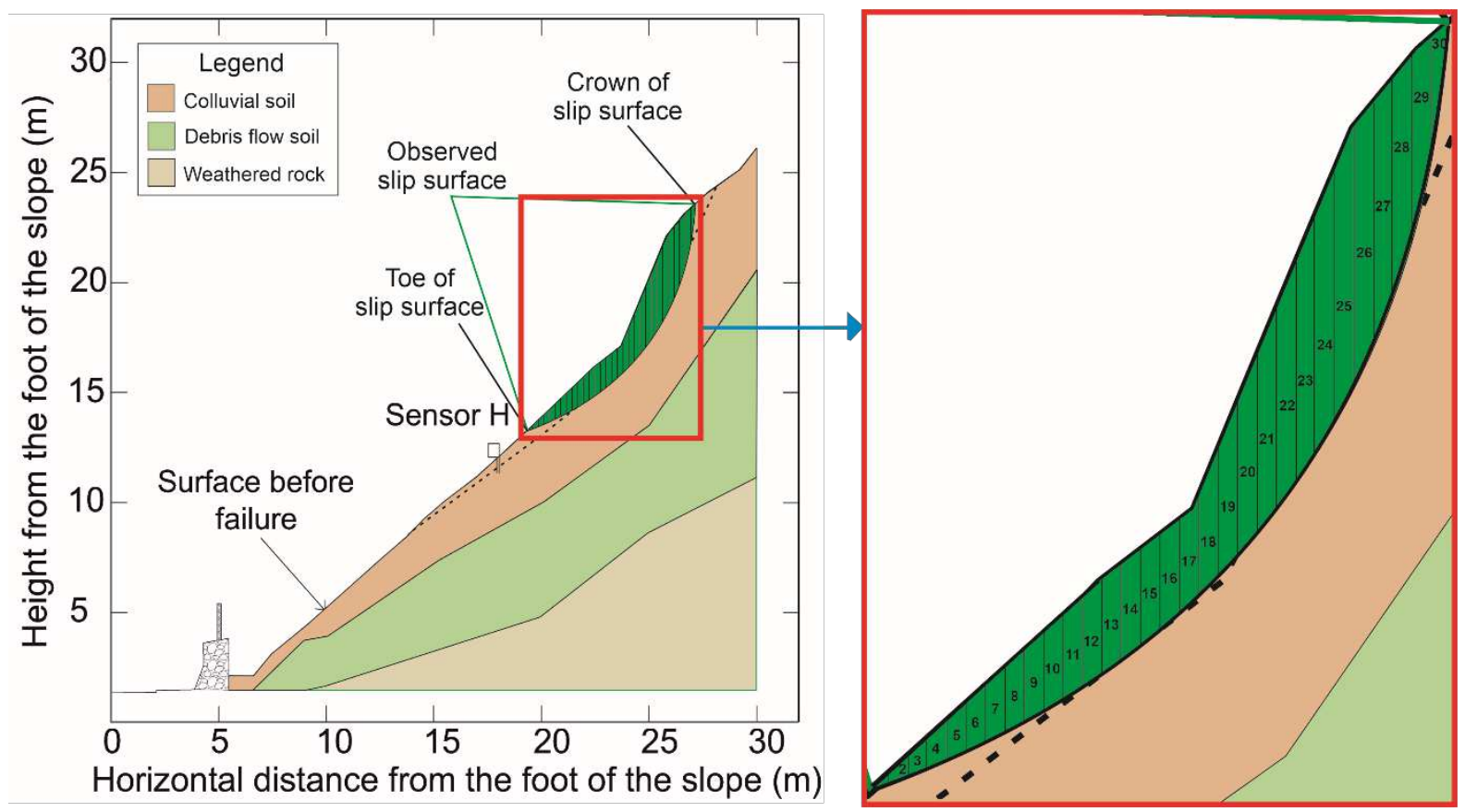

Fig. 22 The observed slip surface from site investigation 


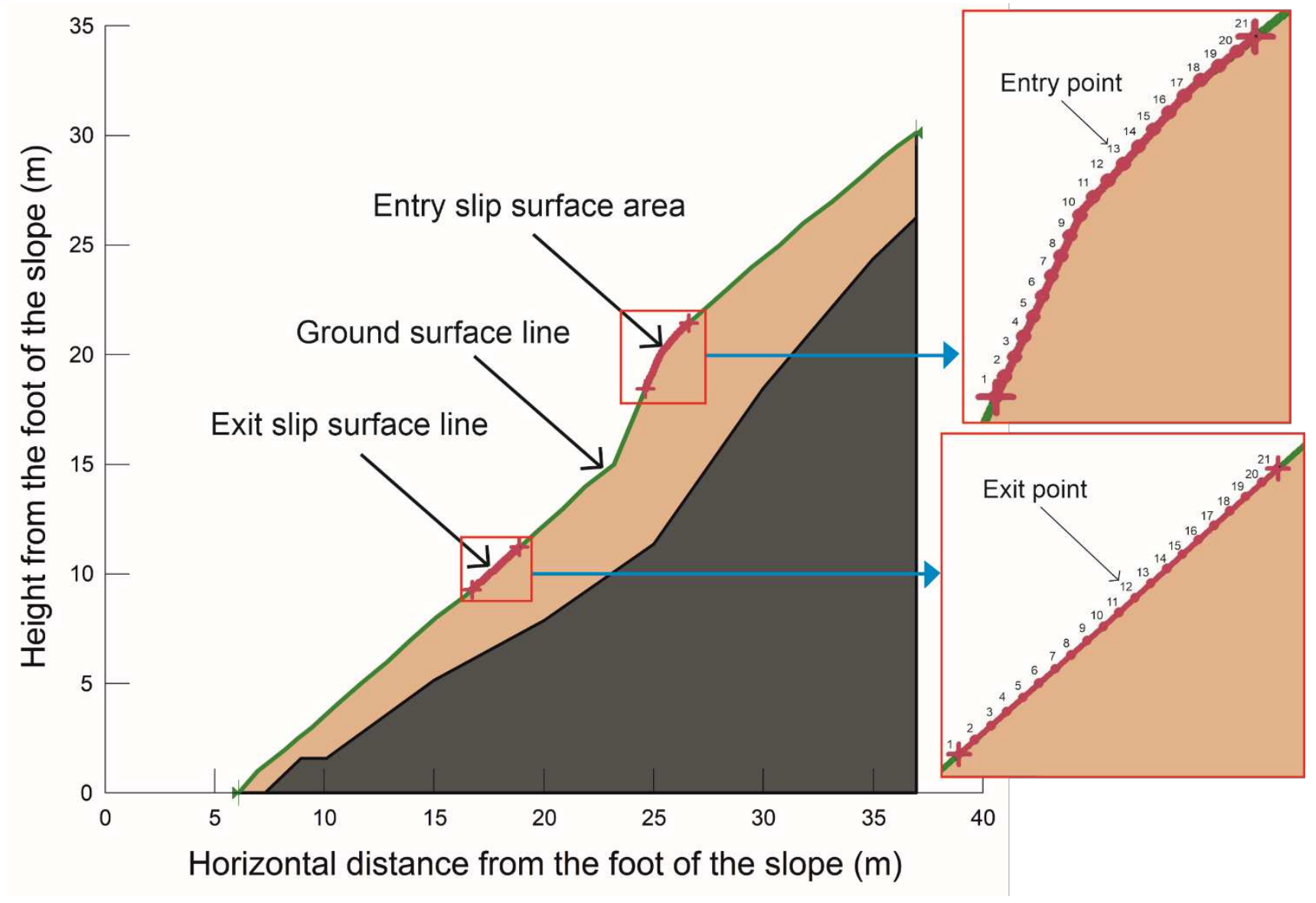

Fig. 23 Geometry of the slope for the SLOPE/W simulation 


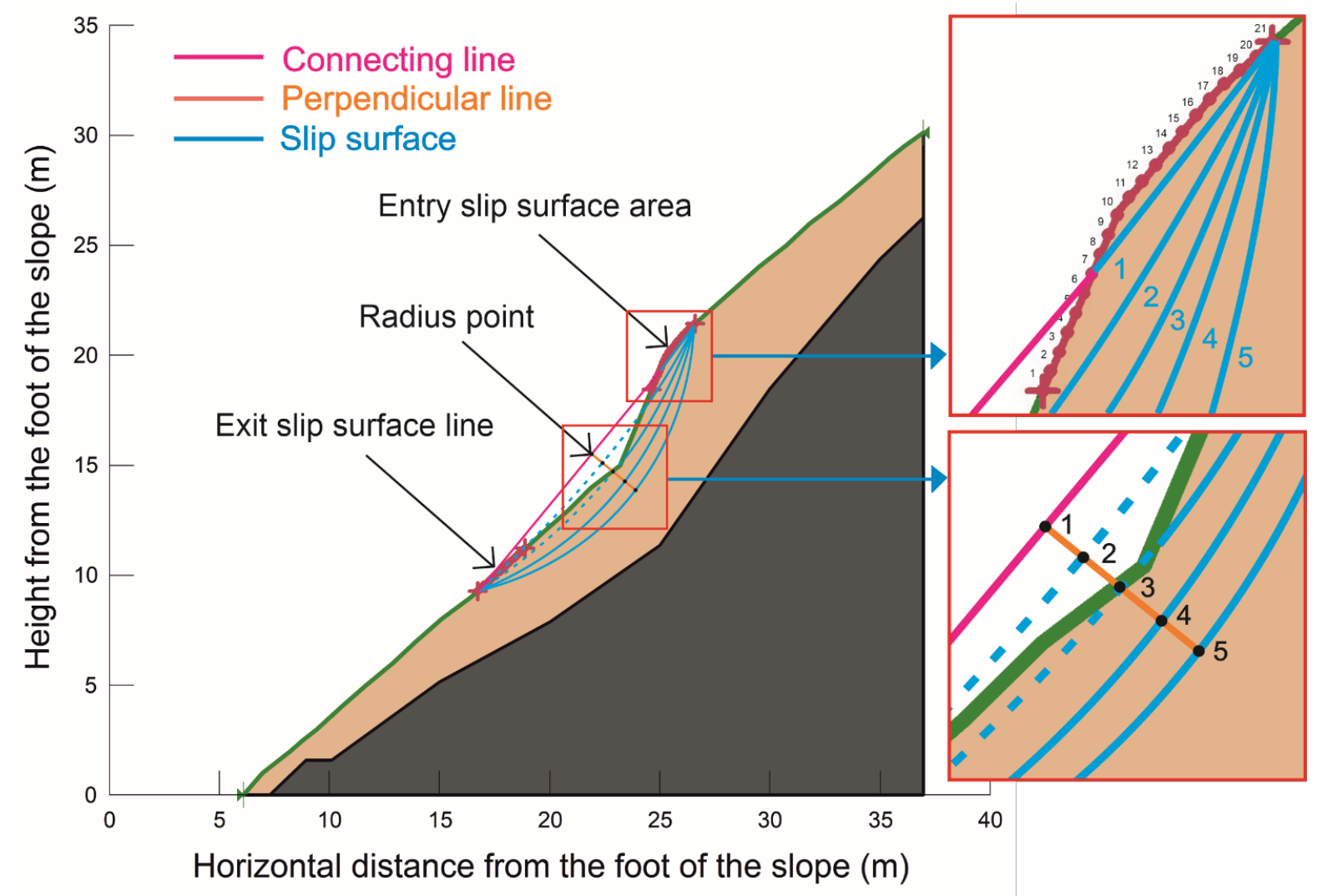

Fig. 24 The trial slip surfaces between entry point no.21 and exit point no.1 


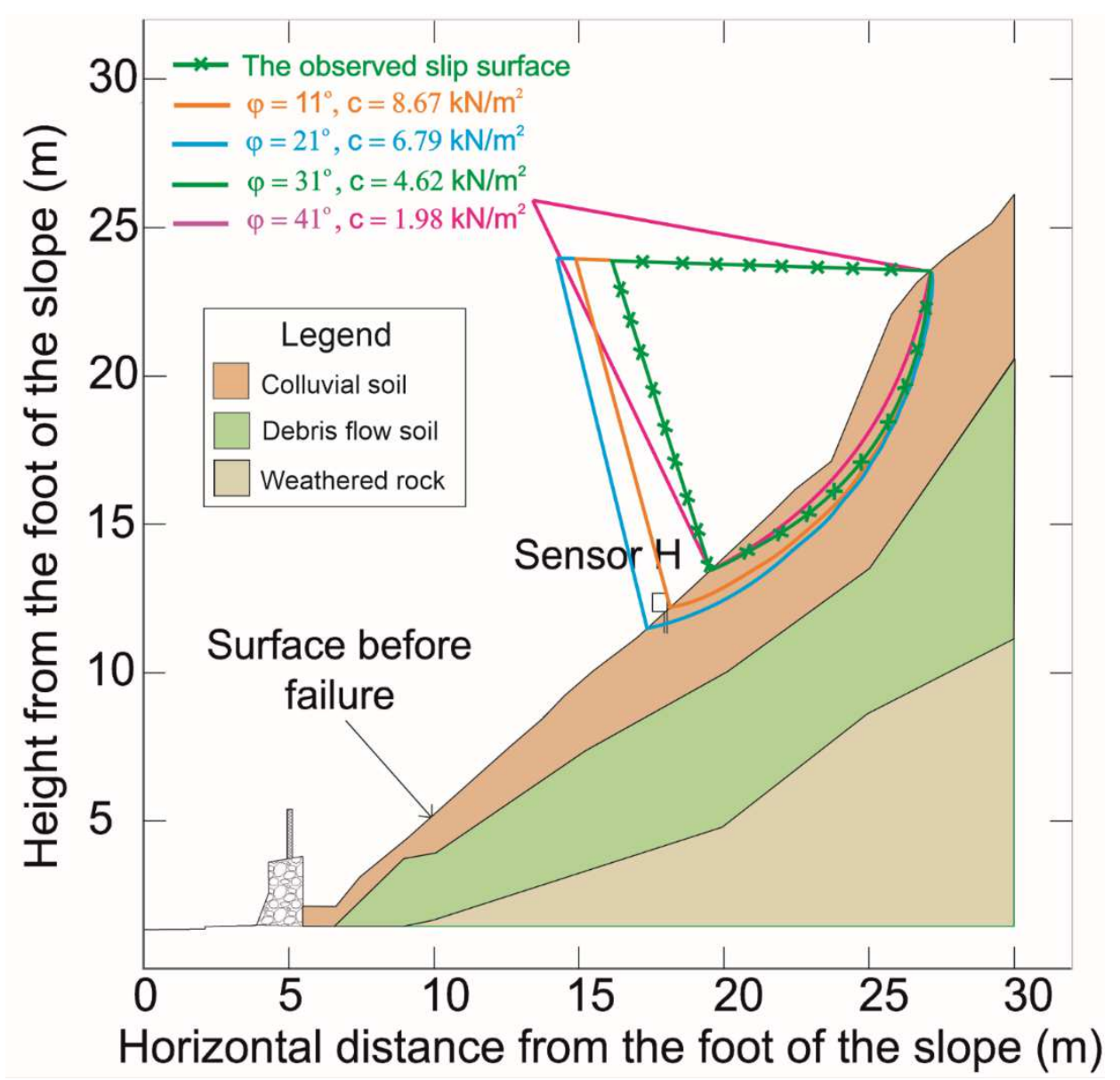

Fig. 25 Critical slip surface for each shear strength parameter and observed slip surface 


\section{Table Captions}

Table 1 Candidate sites for gateway device

Table 2 Displacement data

Table 3 Soil classification based on sieve analysis

Table 4 The safety factor for each shear strength parameter 
Table 1 Candidate sites for gateway device

\begin{tabular}{ccc}
\hline Point & Elevation $(\mathrm{m})$ & Distance from transmitter $(\mathrm{km})$ \\
\hline Observation site & $115-150$ & - \\
\hline Location 1 & 15 & 15.40 \\
Location 2 & 510 & 8.30 \\
Location 3 & 350 & 8.80 \\
Location 4 & 850 & 8.20 \\
\hline
\end{tabular}


Table 2 Displacement data

\begin{tabular}{|c|c|c|}
\hline \multirow{3}{*}{ Day } & No. 2 (Sensor F) & No 3 (Sensor I) \\
\hline & $4.00-10.00 \mathrm{~m}$ & $4.50-7.00 \mathrm{~m}$ \\
\hline & Displacement (mm) & Displacement (mm) \\
\hline $2018 / 2 / 13$ & 29.39 & 17.99 \\
\hline $2018 / 3 / 14$ & 30.93 & 18.86 \\
\hline $2018 / 4 / 25$ & 33.84 & 20.43 \\
\hline $2018 / 5 / 11$ & 35.44 & 21.82 \\
\hline $2018 / 6 / 29$ & 39.10 & 24.06 \\
\hline $2018 / 7 / 27$ & 52.26 & 30.18 \\
\hline $2018 / 8 / 22$ & 53.95 & 30.90 \\
\hline
\end{tabular}


Table 3 Soil classification based on sieve analysis

\begin{tabular}{|c|c|c|c|c|c|c|}
\hline Point & $\begin{array}{c}\text { D10 } \\
(\mathbf{m m})\end{array}$ & $\begin{array}{c}\text { D30 } \\
(\mathbf{m m})\end{array}$ & $\begin{array}{c}\text { D60 } \\
(\mathrm{mm})\end{array}$ & $\begin{array}{c}\text { Cu } \\
\text { (Coefficient of } \\
\text { uniformity) }\end{array}$ & $\begin{array}{c}\text { Cc } \\
\text { (Coefficient of } \\
\text { gradation) }\end{array}$ & Code \\
\hline S-1 & 0.004 & 0.01 & 0.13 & 31.88 & 0.24 & SP \\
\hline S-2 & 0.009 & 0.05 & 0.23 & 25.34 & 1.10 & SW \\
\hline S-3 & 0.060 & 0.04 & 0.63 & 10.40 & 0.04 & SP \\
\hline S-4 & 0.020 & 0.17 & 0.53 & 26.38 & 2.80 & SW \\
\hline S-5 & 0.010 & 0.05 & 0.31 & 32.63 & 0.82 & SP \\
\hline S-6 & 0.040 & 0.11 & 0.48 & 11.88 & 0.68 & SP \\
\hline S-7 & 0.012 & 0.11 & 0.23 & 19.57 & 4.34 & SP \\
\hline
\end{tabular}

- SW : Well-graded sand $(\mathrm{Cu} \geq 6$ and $1 \leq \mathrm{Cc} \leq 3)$

- SP : Poorly graded sand $(\mathrm{Cu}<6$ and/or $\mathrm{Cc}<1$ or $\mathrm{Cc}>3)$ 
Table 4 The safety factor for each shear strength parameter

\begin{tabular}{cccc}
\hline $\begin{array}{c}\text { Shear strength parameters fixed } \\
\text { by manual analysis }\end{array}$ & \multicolumn{2}{c}{ Safety factor } \\
\hline$\phi\left(^{\circ}\right)$ & $c\left(\mathrm{kN} / \mathrm{m}^{2}\right)$ & $\begin{array}{c}\text { Predetermined for } \\
\text { manual analysis }\end{array}$ & $\begin{array}{c}\text { Obtained from } \\
\text { SLOPE/W }\end{array}$ \\
\hline 11 & 8.67 & 1.000 & 0.925 \\
21 & 6.79 & 1.000 & 0.943 \\
31 & 4.62 & 1.000 & 1.000 \\
41 & 1.98 & 1.000 & 0.993 \\
\hline
\end{tabular}

